\title{
THE UNFORTUNATE REGRESSIVITY OF PUBLIC NATURAL DISASTER INSURANCE: QUANTIFYING DISTRIBUTIONAL IMPLICATIONS OF EQC BUILDING COVER FOR NEW ZEALAND
}

BY

SALLY MARGARET FREAN OWEN

A thesis

submitted to the Victoria University of Wellington

in partial fulfilment of the degree of

Master of Commerce (Economics)

Victoria University of Wellington

(2017) 


\begin{abstract}
:
This thesis examines the question "What have been the distributional implications of the setup of Earthquake Commission (EQC) building cover for New Zealand homeowners?" In New Zealand, the vast majority of property owners pay identical premiums for the benefit of the first $\$ 100,000$ tranche of natural disaster cover per dwelling. The research provides a detailed quantification of the degree of regressivity of the scheme created by these flat premiums. Using EQC claims and property datasets relating to the Canterbury Earthquake Series, I test the hypothesis that wealthier homeowners are receiving more benefit. Wealth is identified by property value, income and a range of socio-economic variables collected from the most recent New Zealand Census before the earthquake series. In explaining EQC total dwelling payout by property value and by these socio-economic variables, the research shows there is a distributional implication to EQC's building cover. This thesis includes a proposed modification to the premium structure of the scheme, whereby regressivity could be avoided. The research concludes with a survey of other public natural disaster insurance schemes worldwide, and identifies those likely to face similar regressivity issues.
\end{abstract}




\section{Acknowledgements:}

Firstly, I'd like to acknowledge my supervisor Professor Ilan Noy. Professor Noy is Chair in the Economics of Disasters at Victoria University of Wellington, and has been a constant source of guidance, support and encouragement.

Thank you also to the EQC for supplying the data for this research, and to EQC staff for answering many questions of clarification.

I'd also like to acknowledge the support of my partner, Nathan Kok, and parents Nicola Frean and Rhys Owen. Thank you for your wonderful support and never-ending willingness to listen to me talk about insurance - not the most user-friendly topic. 


\section{Contents}

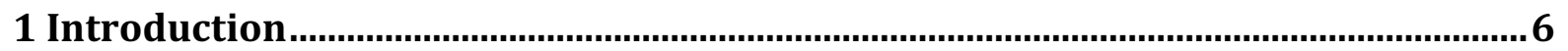

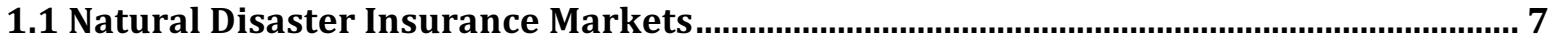

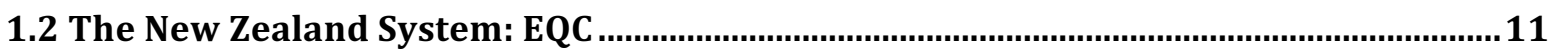

1.3 Literature Review on Regressivity and Public Natural Disaster Insurance ...................13

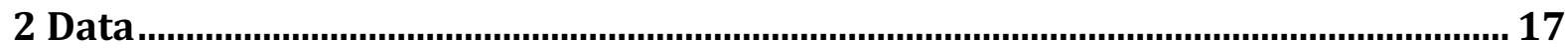

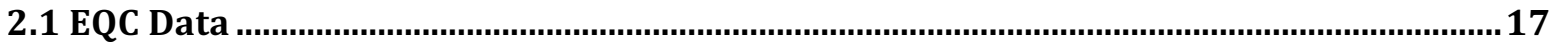

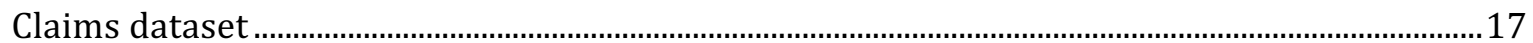

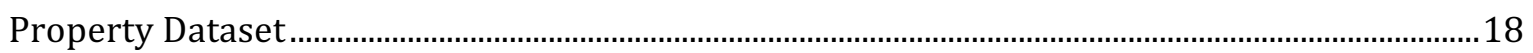

Combining these two EQC datasets ...................................................................................................19

2.2 Statistics New Zealand Data

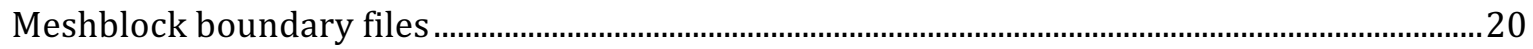

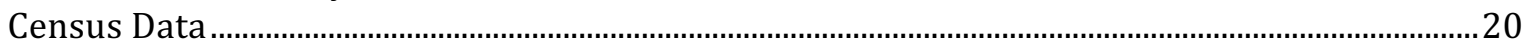

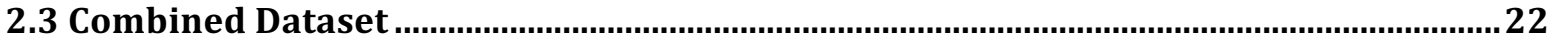

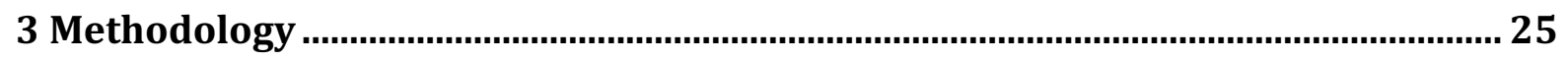

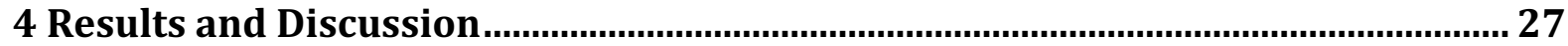

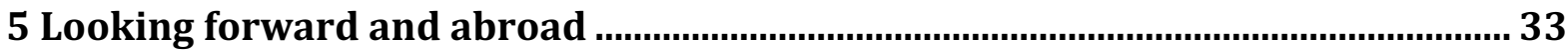

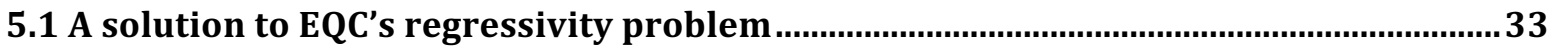

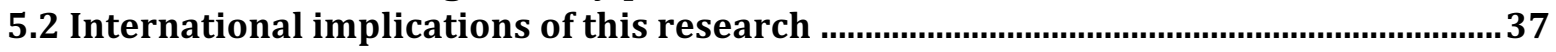

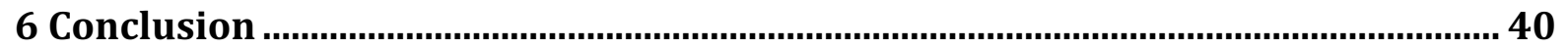

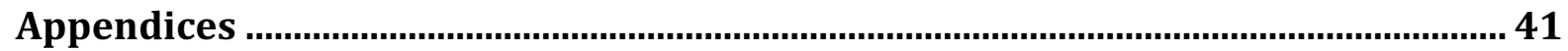

I - The difference between OLS regression and quantile regression ......................................41

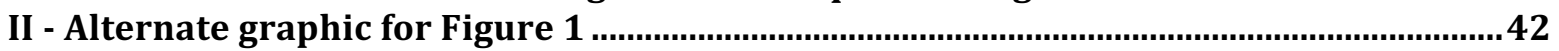

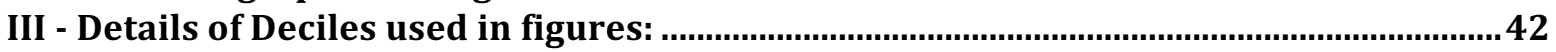

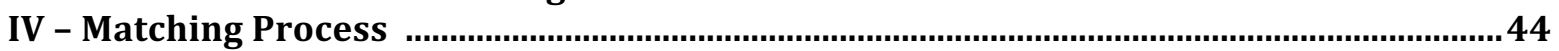

V - Suggested Premium to Total Payout ratios by alternate deciles......................................45

VI - \$150/Total Payout ratios, by property value and income deciles ................................46

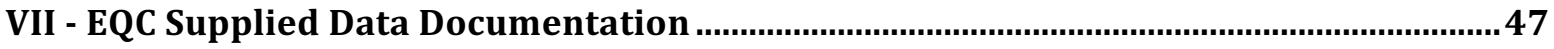

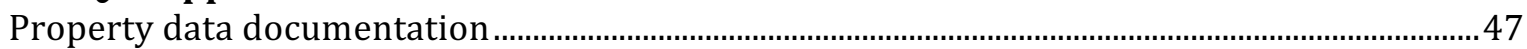

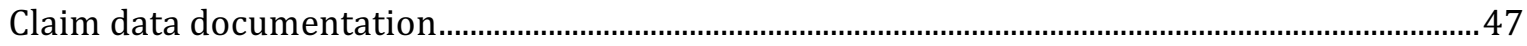

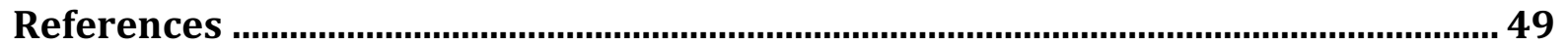




\section{List of Figures:}

Figure 1: Distribution of Dwelling Payouts by Property Value and Income deciles. ........24

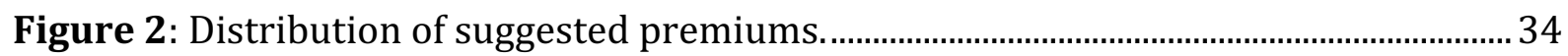

Figure 3: Premium to Payout Ratio for suggested premiums, by Building Value Decile 35

Figure 4: Distribution of Adjusted Building Payouts by Property Value and Income deciles - version 2

Figure 5: Premium to Payout Ratio for suggested premiums, by Median Household Income Decile 45

Figure 6: \$150/Total Building Payout by Building Value Decile then Median Household Income Decile 46

\section{List of Maps:}

Map 1: Mapped properties with claims, zoomed to Canterbury region.

\section{List of Tables:}

Table 1: Summary Statistics. 23

Table 2: OLS Regression Results 30

Table 3: Specification testing 31

Table 4: Quantile Regression Results 32

Table 5: Public and Public-Private natural disaster insurance systems for personal property.

Table 6: Summary Statistics of Dwelling-Adjusted Property value, by decile

Table 7: Summary Statistics of Meshblock Median Household Income as of 2006, by decile. 


\section{Introduction}

The research question this thesis sets out to answer was "What have been the distributional implications of the setup of EQC building cover for New Zealand homeowners?"

The thesis is the first to provide a detailed quantification of the degree of regressivity of a public natural disaster insurance scheme. The New Zealand (NZ) insurance scheme enables this for two main reasons:

1. The data available after a large event (the series of Canterbury earthquakes in 2010-11 that led to a large volume of claims);

2. The well-established success of this program in achieving wide-spread coverage - the Canterbury earthquakes were the most insured large-scale events ever ${ }^{1}$;

In spite of the egalitarian aim of this scheme (all households pay functionally identical premiums) and the egalitarian distributional policy of past and present NZ governments, I find the NZ scheme regressive as it is currently structured, and report on the extent of this unfortunate regressivity.

In this introduction I introduce the concepts surrounding natural disaster insurance, explain why it is often left to the public market, discuss what a "good" insurance system might look like, and then describe how the New Zealand scheme is set up. I continue with a (necessarily brief through lack of content) literature review of the other economic studies touching on regressivity in public natural disaster insurance systems. In section two I describe the data, and section three explains the methodology. In section four I report the extent of regressivity in the scheme as it is manifested in the building cover insurance claims that resulted from the Canterbury earthquakes, using OLS and quantile regression models. I regress the total payout on a property, adjusted by the number of dwellings, against a number of covariates. Those covariates include dwelling-adjusted property value (pre-quakes) for that specific property, and a number of the most recently reported meshblock level socio-economic and ethnicity proxies: median household income, proportion tertiary educated, proportion of the area identifying as Māori, proportion of the area identifying as Pasifika or proportion of the

\footnotetext{
1 The three highest cost earthquakes in the Canterbury sequence are among the top 10 costliest earthquakes for 1980-2015 (by insured losses) globally. Relative to damages, these events were at least twice as well insured as any of the others on the list (MunichRe, 2016).
} 
area identifying as born outside New Zealand, mean number of household members, the proportion who do not own their home, and the difference between the most recent and second most recent reports of median household income. I find that for every NZ\$ 10,000 of higher property value, on average approximately $\$ 257$ more has been paid out from EQC, holding all else constant. This clearly shows that even though EQC payouts are capped, homeowners who have larger homes are receiving more benefit from the $\$ 150$ premium per annum than their less affluent counterparts. In section five I suggest a way that this regressivity can be remedied by a modification to the current structure of the program, and discuss the implications of this research for other countries with public natural disaster insurance systems. Finally, I give a brief conclusion to the thesis.

\subsection{Natural Disaster Insurance Markets}

Economists differentiate between uncertainty and risk, as first defined by Knight (1921). Risk applies to situations where the outcome of a given situation is unknown, but can measure the odds. By contrast, uncertainty applies to situations where we cannot know all the information we need.

Insurance markets work best when losses from a particular hazard are independent of each other, and the insurer has accurate information on the likelihood of the event occurring. In other words, where there is risk but not uncertainty. Unlike terrorism or alien invasion, natural hazards are what is called in insurance a known risk. A known risk is where there is a significant amount of data available to estimate the likelihood of an event and the damage it may cause. In economic terms, a known risk has little uncertainty. Terrorism, on the other hand, is called as an unknown risk, as the likelihood and consequences are not able to be estimated due to limited data. In other words, there is uncertainty. Alien invasion is classed by insurers as an unknowable risk, where there is simply no way to determine the likelihood. What being a known risk means is that natural hazards should be easier to insure against than some other perils.

However, there are still significant difficulties with insurance against natural hazards. ${ }^{2}$ For an insurer to offer coverage against a known risk it needs to determine a premium that yields a positive expected profit, as well as avoiding an unacceptable level and probability of loss (Kunreuther \& Pauly 2009). Herein lies the issue: two problems

\footnotetext{
2 The term natural disaster insurance is used by EQC. In the international literature this type of insurance is known as disaster insurance, catastrophe insurance, or natural hazard insurance. I use natural disaster insurance for consistency with EQC's terminology.
} 
that an insurer faces in setting premiums for catastrophic losses are uncertainty in loss and highly correlated risks. Insurers face uncertainty in loss because of the risk of extreme events. Further, the risks for each individual property are correlated, so there are many claims occurring at the same time.

In the face of these challenges, not many private markets exist for natural disaster insurance. Those that do are in low risk countries, and do not have widely considered affordable rates. Looking back, there are multiple examples of failed private natural disaster insurance markets: flood and earthquake insurance in the United States (US) are two prominent ones. Many of the examples of withdrawals from the private insurance markets involve private insurers who did not have enough information regarding loss, and hence folded after a major event. From the US for example, flood insurance was first offered in 1897 in Cairo, USA, but was abruptly stopped after the Mississippi and Missouri Rivers flooded the insurers' office. In the 1920s it was offered again when fire insurance companies began to include flood cover, but not for long. The loss following extreme flooding in 1927-28 led all companies to discontinue (Manes 1938). Wind damage also led to enormous losses. For example, after Hurricane Andrew insurance against wind was dropped by some insurers in Florida. The high rates that would be required to continue writing coverage with a positive expected profit were thought to be under threat by regulation. Insurers who wrote large amounts of coverage in Florida were also worried about catastrophic losses following the next hurricane. For example, State Farm and Allstate Insurance paid $\$ 3.6$ billion and $\$ 2.3$ billion in claims in the wake of Hurricane Andrew, due to their high concentration of homeowners' policies in the Miami/Dade County area of Florida. Both companies and other insurers began to reassess their strategies of providing coverage against wind damage in hurricane-prone areas (Lecomte \& Gahagan 1998).

Not all private natural disaster insurance markets fail. However, those private markets which exist (such as in Germany) seldom succeed in providing widespread coverage (Kunreuther and Pauly, 2009; Kusuma, Nyugen and Noy, 2017). In fact, no country in the world has a free market for flood insurance which provides affordable cover for high risk households without some form of Government involvement (ABI 2011b).

The concept of pooling resources and sharing costs is a fundamental principle of insurance. We see this type of redistribution often, for example it is common that one person subsidizes the medical treatment of their neighbour, another contributes to the 
education of their neighbour's children and an urban resident subsidizes the cost of postal delivery to someone living in a remote area. Natural disaster insurance arguably falls into the same basket (Morpeth, 2010). Public catastrophe insurers aim, similarly, for one citizen with lower risk of natural hazard incurred loss to subsidize another who is more vulnerable to losses.

A good insurance system incentivises risk reduction and enables the insured party to take on beneficial and productive business risk and investment ex ante; ex post, it allows the insured party to avoid some of the financial loss, avoid destitution, and recover more quickly and more fully. O'Neill \& O'Neill (2012) argue further that insurance should ensure the security of at least a class of basic goods required by social justice, independently of the risks and risk-taking of individuals; with housing being a prime example. Housing in particular is a gateway social good (O’Neill 2006), which protects one's access to other essential elements of a worthwhile life, and because of this, there are weighty reasons to make sure that all citizens have secure access to natural disaster insurance for their property. From a communitarian rather than an individualist perspective, the inability of some households to rebuild post disaster imposes additional harm on the rest of the community. Thus, if there is no provision of natural disaster insurance by the private market, both individualist and communitarian governments have clear rationales for intervention to facilitate residential natural hazard insurance coverage for all. Governments can pursue that aim by either insuring directly or subsidizing the private insurance sector, and have chosen to do so in many countries. ${ }^{3}$

A further reason to intervene is that catastrophes impact the vulnerable most. Loss of a secure home, health effects, dislocation of local communities, disruption of education and work are all consequences of catastrophic events. These impacts are worse for those with fewer resources, who tend to be more vulnerable (Lindley et al 2011). For example, in floods the poor, the old, children, the disabled and women suffer the harshest impacts, and these can be long-lasting (Dlugolecki et al. 2009). Unfortunately, these groups are most likely to be under- or un- insured. Affordable insurance mitigates this. Governments need to help develop sustainable subsidy models which are paid for by taxpayers, by low risk households or both (ABI 2011b).

\footnotetext{
${ }^{3}$ Belgium, France, Japan, New Zealand, Spain, Switzerland, Turkey, UK, and the USA to name a few. See Table 5: Public and Public-Private natural disaster insurance systems for personal property.
} 
There have been a number of academic contributions regarding the ideal system. Paudel (2012) provides recommendations for designing public or public-private natural disaster insurance schemes. His recommendations include: mandatory participation; adequate enforcement to ensure compliance; public responsibility for the higher tranches (the catastrophic end) of the insured risk; private sector administration of policies; public provision of subsidies through for example tax exemptions; public investment in risk mitigation; a (publicly provided) detailed assessment and mapping of risk; and the provision of financial incentives for policyholders to take risk mitigation measures. Kunreuther and Pauly (2009) are more specific. They suggest a multi layered public-private programme. Similar to having an excess (or deductible), the first level of loss would be borne by the homeowner to encourage their adoption of mitigation methods and avoid moral hazard problems (if individuals behaved more carelessly because they knew they were fully protected against the risk). Then the second level would be borne by the private insurers, with the amounts of coverage based on their surplus, their current portfolio and their ability to diversify across risks. Layer three would consist of private sector risk transfer mechanisms, including reinsurance and catastrophe bonds. (With a catastrophe bond, if the losses exceed a certain amount, then the interest on the bond, the principal, or both, are forgiven.) Finally, layer four would cover large-scale losses, using multi-state pools for providing coverage in certain regions subject to particular hazards.

Most economists also argue that insurance premiums should be risk-based (see for example Bin, Bishop \& Kousky, 2010, O'Neill \& O'Neill, 2012 and Kunreuther, 2015). Risk-based insurance premiums signal to residents and businesses the hazards they face and enable insurers to lower premiums for properties where steps have been taken to reduce risk. Risk based premiums, however, do raise equity concerns, and there is some recognition that a fully risk-sensitive insurance regime may be socially or politically unacceptable if it imposes very high costs on some groups (Houston et al., 2011).4

In summary, natural disaster insurance markets are complex due to uncertainty in loss and correlated risks, and private markets have not succeeded. Public markets

\footnotetext{
${ }^{4}$ Kunreuther (2015) suggests that to address issues of equity and fairness, homeowners who cannot afford insurance could be given vouchers tied to loans for investing in loss reduction measures, but this kind of voucher program is yet to be implemented anywhere. Another suggestion is a universal 'Community Flood Levy', based for example at a percentage of the premium. This could be charged on all household insurance policies. Then those with higher risk would be subsidized, but the levy could be low enough to be affordable (O’Neill \& O’Neill 2012).
} 
exist, and in the literature there is preference for risk-based premiums even in these public markets.

Given the dominant role of the public sector in the provision of disaster insurance, and the evident concern worldwide about growing income and wealth inequality, it is surprising that equity issues have not faced more scrutiny with respect to publicly provided disaster insurance. For example, this aspect of the recently launched UK government FloodRe program has received almost no attention, in spite of the potentially very regressive structure of that program.

\subsection{The New Zealand System: EQC}

In NZ, public disaster insurance is provided to the vast majority of residential home owners by the Earthquake Commission (EQC). In order to access this insurance, homeowners need only have private fire insurance (which over 90\% do). This implicit disaster insurance is called EQ Cover. Like the Community Flood Levy suggestion, EQC premiums are practically flat. EQ Cover premiums are identical for all dwellings insured for more than 100,000 NZ\$ (and almost all are). These premiums are collected through the homeowner's private insurer and passed on to EQC's Natural Disaster Fund (NDF). EQC operates on a dual insurance model, meaning both EQC and the private property insurers share insurance obligations (NZ Treasury 2015).

To fully appreciate the role EQC plays, it is important to consider how it developed.

In 1906 San Francisco was hit by a devastating earthquake, which affected German insurers particularly hard. In the wake of this tragedy, much of the global insurance industry responded by ruling out earthquake and related fire damage (Henderson, 2010). In 1931, NZ was struck by an earthquake centred on Napier. At this time private earthquake insurance was available in NZ, but was voluntary (NZNSEE, 1993). In the aftermath, NZ suggested extending its system of fire levies, collected by the insurance sector to pay for fire brigades, to also cover disaster restoration. Unfortunately, it was not yet put in place. Then in 1937, with WWII looming, war damage was also generally excluded from private insurance contracts.

On 19 December 1941 the War Damage Commission was established, under the provisions of the War Damage Act. In 1942, NZ was again hit by another damaging earthquake in the Wairarapa (not far from the capital). On 1 January 1945, the War 
Damage Commission became the Earthquake and War Damage Commission, the precursor to the present EQC. Part of the motivation for its establishment were the slow rates of repair following the 1931 and the 1942 events (NZ Treasury 2015). The main objective of the Earthquake and War Damage Commission was to provide compulsory war and earthquake insurance for all properties.

On 1 January 1994 the Commission was again reconstituted under the Earthquake Commission Act 1993 which recreated the scheme, now colloquially known as EQC. It acknowledged the scheme to be primarily for the purpose of natural disaster relief, and a major development in the Act was the phase-out of non-residential property insurance. It also amalgamated the War Damage and Earthquake Fund and the Disaster and Landslip Fund as the Disaster Fund. This is the fund EQC draws out of to pay out on claims.

The EQC currently provides three forms of insurance cover to residential property owners: structure, land, and contents. These are insured to replacement value against natural hazards such as earthquake/tsunami, volcanic eruption, and landslip. Due to the geography of New Zealand, the vast majority of claims are related to earthquakes (of the 543,531 claims since $1980,94.9 \%$ were related to earthquakes). The cover for residential buildings provides the first NZ\$100,000 of replacement value for each insured dwelling. ${ }^{5}$ If the loss is greater than this, the private insurer is responsible for any over-cap repair costs. As the analysis below focuses only on structural damage claims (and not contents or land), it only describes this part of EQC policy; the details about land insurance, uniquely covered in NZ, are significantly more complicated. For each NZ\$ 100 of property insured by the EQC, a levy is charged by the private insurer and sent to EQC. In 1993, these premiums were set at $0.0005 \%$ of property insured, but were tripled after the Canterbury earthquakes of 2010-11 to 0.0015\%. In November 2017, these will increase again to $0.002 \%$, due to another earthquake centred in Kaikoura. ${ }^{6}$ More than $99 \%$ of homes are valued at more than NZ\$ $100,000^{7}$, so in effect all pay the same amount to EQC.

In order to quantify the regressivity of the EQC cover, I require indicators of the share of wealth being used for premiums and the amount of value returned by the EQC

\footnotetext{
${ }^{5}$ A multi-unit residential building covered for fire damage would be insured through EQC for the first NZ\$ 100,000 times the number of dwellings in the building.

6 See https://www.eqc.govt.nz/news/budget-announcement-eqc-levy-to-increase

${ }^{7}$ Statistic drawn from the EQC Property dataset.
} 
scheme. Naturally, there is some value in the certainty of knowing one is insured regardless of whether that insurance is ever required, and some value in support for the over-cap private natural disaster insurance market. However, for the purposes of this analysis, value is defined as actual payout to the owner for disaster damage. This value is assumed identical for all, and since everyone pays the same, the equity question is reduced to: Have wealthier homeowners received more money from EQC for building repair than their less-well-off counterparts?

\subsection{Literature Review on Regressivity and Public Natural Disaster Insurance}

Fairness has been widely discussed in the evaluation of taxation (e.g., Simons, 1938; Goode, 1980). Economists have generally recognised two principles of fair taxation: a benefit principle, and an ability to pay principle. The benefit principle states that taxes should be levied such that benefits received (from the tax revenue) by the payers are proportional to their tax burden. Under this concept of fairness, there is no role for redistribution. Examples include motor fuel excise tax that is used to fund highway construction and maintenance. The ability to pay principle focuses only on the cost side, and ignores the distribution of benefits. It views taxation as imposing a cost that should be allocated such that it taxes those with equal ability to pay equally (horizontal equity), and imposes greater burdens on those with greater ability to pay (vertical equity). ${ }^{8}$

The concept of regressivity was originally applied to income tax systems. As defined in Kakwani (1977), if $\mathrm{T}(\mathrm{x})$ is the tax paid by an individual with income $\mathrm{x}$; the tax system is proportional when the elasticity of $\mathrm{T}$ with respect to $\mathrm{x}$ is equal to one for all $\mathrm{x}$, the tax system is progressive when the elasticity exceeds one, and regressive when the elasticity is less than one. This is equivalent to saying that a tax system is progressive, proportional and regressive when the marginal tax rate is greater, equal and less than the average tax rate, respectively. ${ }^{9}$ Kakwani uses only the Gini index to measure the distributional effects of taxation, but presents an alternative measure using the Lorenz

\footnotetext{
${ }^{8}$ Ability to pay is generally measured by annual income. There is no agreed upon standard to determine what vertical differentiation in tax liabilities is most fair (Joint Committee on Taxation, 2015).

${ }^{9}$ Slitor (1948) used this type of definition to propose a measure of progression: $\operatorname{dt}(\mathrm{x}) / \mathrm{dx}=[\mathrm{m}(\mathrm{x})-\mathrm{t}(\mathrm{X})] / \mathrm{x}$; where $t(x)$ is the average tax rate at the income level $x$ and $m(x)$ is the marginal tax rate at that level of income.
} 
Curve $^{10}$ and a created measure of the concentration of taxes to measure both the distributional and proportional elements of a tax system.

Musgrave and Thin (1948) previously created a universal measure of progressivity by comparing the inequality of before-tax and after-tax income distributions. By this measure, a progressive tax system creates a decrease in income inequality, while regressive tax rates will be reflected by increases in income inequality. The authors conclude that if the Gini index is used to measure inequality, the ratio of the Gini indices of the before-tax and after-tax incomes provides a single measure of tax progressivity. 11

Previous work has looked at the regressivity of explicit tax schemes; examples include "sin" taxes ${ }^{12}$ and carbon taxation ${ }^{13}$. This type of analysis is also being used to study implicit taxes and subsidies. For example, Davis and Knittel (2016) investigate whether fuel efficiency standards are regressive, and Johnson (2006) looks at public spending on higher education.

The practical implications of regressivity in public disaster insurance in terms of benefits (paid claims) relative to costs (premiums paid) have not been quantified before. There is however some literature on the potential distributional aspects on two countries.

For the US there are four major academic contributions. Ben-Shahar and Logue (2015) examine Florida's state-owned Citizens' Property Insurance Corporation ("Citizens'”) and its coverage for wind-damage (hurricanes). Their work relies on Citizens' own calculation of the actual risk it takes on when providing insurance and on the premium it charges. They find that the higher subsidies are provided for areas incurring more risk, and that these areas are generally (statistically) wealthier, most likely as they are located closer to the coast. The remaining contributions consider the National Flood Insurance Program (NFIP) in the US. In that program, the federal

\footnotetext{
10 Suppose income $\mathrm{x}$ of an individual is a random variable with mean $\mathrm{u}$ and probability distribution function $\mathrm{F}(\mathrm{x})$. If $\mathrm{F} 1(\mathrm{x})$ is the proportion of income of units having income less than or equal to $\mathrm{x}$, then the relationship between $\mathrm{F}(\mathrm{x})$ and $\mathrm{F} 1(\mathrm{x})$ is called the Lorenz curve of income $\mathrm{x}$.

11 Kakwani (1977), however, pointed out that by doubling the tax rates at all income levels, the tax progressivity would mechanically increase when using the Musgrave-Thin ratio. This is problematic because progressivity (or regressivity) is supposed to measure the deviation of a tax system from proportionality. Kakwani proposes to use the Gini index only to measure the distributional effects of taxation, and presents an alternative measure using the Lorenz Curve to create a measure that accounts for both the distributional and proportional elements of a tax system.

12 Poterba (1991a), Lyon \& Schwab (1991), Bento et al. (2012), and Borren \& Sutton (1992).

13 Wier et al (2005), and Poterba (1991b).
} 
government sells flood insurance policies to property owners. These policies are subsidized, because the premiums collected cannot safely cover flood claims. McGuire et al. (2015) study possible distributional implications of the NFIP by comparing average premiums to average property values (of covered properties) within municipalities. They create a municipal insurance ratio of average premiums over average property values. Their methodology is to then linearly regress the insurance ratio on the average property values. This study concludes that the NFIP rate setting of premiums disproportionately favours higher value property owners in Massachusetts, and as such the nature of Massachusetts's flood insurance rate setting is regressive. A second paper by Bin, Bishop \& Kousky (2012) also studies the NFIP. They focus on the departure from proportionality measure of progressivity; a progressive departure from proportionality requires that every premium decile be no larger than the corresponding income decile. The authors show that the departure-from-proportionality index is not significantly different from zero for premiums, implying they are proportional to income. However, they conclude NFIP payments are progressive, but they consider premiums and payments separately, and they conclude neither effect is extreme, and is smoothed over time. Finally, Howard (2016) examines the net social benefits of the NFIP, using data on premiums, claims, policies and grants from 1996-2010. In his more comprehensive analysis he finds that system is "moderately regressive". In these analyses of the NFIP, it is plausible that the distributional aspect arises solely because of the differentiated exposure of wealthier households because of their location on the coasts and the focus here on hurricane damage, as a lot of the NFIP claims arise out of storm-generated wave surges.

There are three major contributions for the UK case. Surminski (2016) and Davey (2015) discuss various distributional aspects of FloodRe, the UK's flood reinsurance programme, which is designed to maintain affordably-priced flood insurance. Both papers identify several ways in which FloodRe may have distributional consequences, but do not quantify them. O'Neill \& O'Neill (2012) discuss flood insurance in the UK (before the launch of FloodRe) and argue for a solidaristic scheme on fairness grounds, acknowledging that risk based premiums would unfairly penalise households who could not be reasonably found to have chosen to live in flood prone areas, noting "choice is voluntary only if it can be reasonably foreseen and the agents have real and acceptable alternatives to it." This statement raises interesting equity questions, as it is likely that those households facing higher risks are actually wealthier (coastally located, situated 
on slopes for better views, etc.) in which case the fairness principle they advocate may lead to the insurance transferring risk from rich to poor households.

Other economists have noted that part of the argument about the ideal insurance system concerns the degree of collective protection for those who are vulnerable to the outcomes of actions for which there is a wider, uneven, but shared, responsibility. To the degree that the increased frequency and intensity of flooding is the outcome of climate change, it is the outcome of actions for which those who are most vulnerable often are the least responsible. There is a double injustice if those with low incomes who are least responsible for greenhouse gas emissions are faced with the largest burdens of policy responses to the problems which emissions create (see Thumim et al., 2011, Lindley et al., 2011).

The following empirical economic investigation of the distributional implications of public natural disaster insurance in New Zealand adds to this literature. Further to quantifying the practical implications of regressivity in public natural disaster insurance in terms of benefits relative to costs, New Zealand's case offers two unique aspects to the discussion:

1. The public insurance intervention in $\mathrm{NZ}$ is different in nature to those in the US and the UK.

2. The major disaster risk is also different: New Zealand homes are primarily at risk of earthquake damage, as opposed to storms or flooding. 


\section{Data}

This section describes the data I use for my quantitative analysis, with detail on how I sort, build and manage the dataset. ${ }^{14}$

\subsection{EQC Data}

The EQC Claims dataset contains transactional information for each individual claim made to EQC. Information includes the event type and date, dates the claim was opened and resolved, the amount paid for or spent on repairing damages, and the modelled values of the building insured. ${ }^{15}$ In the benchmark analysis, I use data pertaining to the Canterbury Earthquake series of 2010-2011.16 EQC also provided access to some of their property dataset, which notably contains the longitude and latitude of each property claimed upon, along with an ID which makes it matchable to the claims set. In the following subsections I detail the process for matching these, along with exclusions and cleaning procedures.

\section{$\underline{\text { Claims dataset }}$}

From the claims dataset I utilise a number of variables. ${ }^{17}$ Firstly, Event type is used to subset for only earthquake related claims. The relevant categories are Earthquake or Fire Following Earthquake. I also make use of claim status, which identifies whether a claim is open or resolved. The dataset also contains a number of dates, including event date, claim open date and claim close date. I use the event date and the building claim close date in particular, after changing them into the Stata date format (known as SIF). Thirdly, I use a number of variables summarising payments made. Date, payment and repair information are categorised into each of the three possible claims: building, contents or land. For this project, because I am interested in the effect of the capped building premiums, only the information from the building exposures is relevant. ${ }^{18}$ The first hurdle was cleaning these variables. Managed Repair Paid was supplied excluding GST, so this was corrected first. Secondly, if a building claim was denied, sometimes the figure was input as zero instead of missing - this was corrected.

\footnotetext{
14 Stata code (.do files) and an explanation of the files' interactions are available upon request.

15 Modelled building value was created by EQC from data produced by Quality Value Inc., a state-owned enterprise providing estimated property valuation data for all taxable properties. I was only able to access these as mid-year annual valuations spanning from 2010 - 2016. In this section, only the 2010 values are useful as they precede the earthquake series.

16 I restrict the aftershock series as ending 11 February 2012, as adopted in Te Ara: the Encyclopaedia of New Zealand (McSaveney 2017).

17 The supplied data documentation from EQC is included in the appendix to this thesis.

18 To be exact, building payout, building net incurred, building claim event date, etc.
} 
Finally, this was cleaned by identifying human errors. ${ }^{19}$ Building Paid also required some cleaning, especially at the upwards end of the dataset. ${ }^{20}$ I also make use of NumDwell, the number of EQC-insured dwellings in this property for this claim. This required some cleaning, with both the upwards and downwards outliers. By using the largest legitimate number of dwellings in the set, the highest of these were tidied up, excepting a handful which were manually corrected. ${ }^{21}$ I then developed a rule for cleaning NumDwell, making use of another variable: EQCBldgSumInsured, the EQC building sum insured. This uses the fact that it can never be higher than 115,000 per dwelling (due to the cap). I also cleaned NumDwell using the Building Paid information, as payout data is more rigorously checked by EQC than dwelling number (since payment data is used by their accounting staff). A cash settlement divided by the number of dwellings insured can also never exceed 115,000. I then am able to build Dwelling Paid as Dwelling Paid ${ }_{i}=$ Building Paid $/$ /NumDwell cleaned.

\section{Property Dataset}

EQC also provided access to their Property dataset. This dataset's key is EQCPropertyGroup, the internal property identifier, for grouping claims into properties. It also contains PortfolioID, an outside key for linking to QV data. This includes MDwellingValue, which is a modelled value of the home ${ }^{22}$, and longitude and latitude data. This variable was created by EQC from nationwide QV data, beginning from Capital Value minus Land Value and then adjusting for further issues, for example annual adjustment. ${ }^{23}$ I am assured ${ }^{24}$ the EQC modelled values are more accurate than QV data. I also use PortfolioID to append the longitude and latitude data for the property. This is rounded to approximately $70 \mathrm{~m}$ to protect the claimants' privacy. Fortunately, the rounding process is not so large as to stop the geo-locating of each property. ${ }^{25}$

\footnotetext{
19 This included, for example, a handful of managed repairs being input as negatives.

${ }^{20}$ For example, some claims had been recorded as land paid amounts when actually identified as building claims, or vice versa.

21 Details of the correspondence with EQC are included where appropriate in the code. Stata code available if desired.

22 The mid-2010 valuation was the earliest able to be released to us, and so on spanning till 2016. These do not take into account appurtenant structures (e.g. sheds). I explored including the modelled valuations of these, however they are randomly assigned based on different percentages of the home value - and thus proved to be relatively useless empirically.

${ }^{23}$ Official capital and land valuations are only made every three years in New Zealand.

${ }^{24}$ Personal communication from EQC staff.

25 This geo-locating was done using a spatial join.
} 


\section{Combining these two EQC datasets}

Beginning with the claim dataset, I match the property information using Portfolio ID as the match ID. I then flag claims associated with the Canterbury Earthquakes using only those claims with Eventdate between 2010-09-04 and 2012-0211 (as used in Te Ara), Region as Canterbury, and Event type as either Earthquake or Fire following Earthquake. ${ }^{26}$ I flag those claims which involved managed repairs. At this point I utilise the difference between Portfolio ID (created by QV) and EQC Property Group to count and then compare the dwellings per address and per land parcel (PropNumDwells and PortNumDwells). I then combine any claim payouts which involved both cash settlement and managed repair. ${ }^{27}$ This creates the variable Building Payout, as below:

$$
\text { BuildingPayout }_{i}=\Sigma_{\mathrm{i}}\left(\text { Building Paid }_{i}+\text { Managed Repair Paid }_{i}\right)
$$

where $i$ denotes claim ID, Building Paid is the final cash settlement for any building claim, and Managed Repair Paid is the total payments made to EQC for managed repairs associated with that claim. I exclude observations where Building Payout is zero. ${ }^{28}$ I then build the dwelling adjusted version, as below:

$$
\text { DwellingPayout }_{i}=\text { BuildingPayout }_{i} / \text { NumDwells }_{i}
$$

I exclude any observation with a missing value for bldg_2010, the mid-2010 modelled building value.

To create the final dataset for the Canterbury earthquake series analysis, this cleaned claim dataset is collapsed by EQCPropertyGroup, such that each observation becomes property-level based on addresses (not on QV land parcels, as is PortfolioID). This ensures that multiple properties on a single land parcel are treated accurately. I use claim level Addresses per Land Parcel and Dwellings per Portfolio to create Property- or Dwelling-adjusted Modelled Building Values. The supplied modelled building values are at the Portfolio ID level, so adjusting down to the EQCPropertyGroup level is imperative. Another variable created in this collapse is Total Building Payout, formulated as below:

\footnotetext{
${ }^{26}$ I exclude building claims noted as still "open". It's possible this introduces some sample selection, however not clearly in one direction or the other. Without accurate payout information however, the analysis is impossible - so this is unfortunately unavoidable.

27 This occurred for a number of reasons, including for example when events happened in such quick succession that a second or third claim could not be disentangled and so were recorded as one.

${ }^{28}$ Early on I did include zero value payouts as an experiment, but found no discernible difference and so exclude them.
} 


$$
\text { TotalBuildingPayout }_{j}=\Sigma_{i} \text { BuildingPayout }_{i}
$$

where $j$ denotes the property, and $i$ denotes the claims associated with that property. I can then form the dependent variable: Total Dwelling Payout, which adjusts for the number of dwellings insured. It is important to normalise by the number of dwellings insured because the cap on EQC building payouts is per dwelling, not per property. So, to compare the total payout of neighbours who had one and two dwellings respectively would generate bias - the neighbour with two can be expected to receive more. The dependent variable is thus:

$$
\text { TotalDwellingPayout }_{j}=\Sigma_{i} \text { DwellingPayout }_{i}
$$

I also create the sum of actual assessed repair costs for each property.

\subsection{Statistics New Zealand Data}

$\underline{\text { Meshblock boundary files }}$

Shapefiles (for use in ArcGIS) of the meshblock boundaries are publicly available. I am able to match each property to a meshblock, which allows the appending of mesh block-level socio-economic data collected from the Census. Note that not every meshblock contains properties that have been claimed upon, as one would expect given the nature of disasters in NZ, and the location of residential properties.

As well as the meshblock boundaries, this file also contains data on various classifications of geographic areas. I make use of an urban area classification. One of these categories signifies a rural area - this is used to create an indicator variable for whether a property is rural or not. I also use the indicators for each island, and each regional council from this dataset.

\section{Census Data}

Next I utilise Statistics New Zealand data from the national Census. Statistics New Zealand provides publicly-available meshblock level information from the New Zealand Census (henceforth "The Census"), conducted in 2001, 2006 and 201329. A meshblock is the smallest unit for which Statistics New Zealand collects data, with boundaries related to population. For my initial analysis I include a number of explanatory variables

\footnotetext{
${ }^{29}$ Censuses are conducted every 5 years. The 2011 census was postponed to 2013 because of the earthquakes.
} 
created from the 2006 Census; being the most recent before the Canterbury Earthquakes struck, and the 2001 Census. I use data pertaining to the personal and household sections of the Census. Specifically, the proportion of the meshblock who identify as Māori ${ }^{30}$ or Pasifika (Pacific Islanders), proportion who self-report that they were born overseas, proportion in the meshblock who self-report having completed tertiary level education, the median household income per meshblock as of $2006^{31}$ (top censored at $\$ 100,000$ ), the change in the median household income between 2001 and 2006, the mean number of household members, and the proportion of the meshblock which self-report as not owning the house. The next subsections describe how I build each of these, grouped by the portion of the Census from which they were collected.

\section{Individual dataset part 1}

To create the proportion of the meshblock who self-report each ethnicity, I take the count of that ethnicity divided by the count who stated any ethnicity in the meshblock. I use the same method to create the Proportion Born Overseas.

\section{Individual dataset part 2}

To create the Proportion University Educated, I first create the number university educated as the total of the counts of each of Bachelor Degree, Level 7, Postgrad, Honours, Masters or Doctorate from the 2006 census. I then divide this by the total number who stated an education level in each meshblock.

\section{Household dataset}

I build the Portion Households Not Owned as the total number of dwellings either held in trust, owned outright or not owned divided by the total available responses, for each of 2001, 2006 or 2013 meshblocks. Median Household income is supplied, as is the Mean Number of Usual Residents of the household. I then create indicators for Censored Income for each meshblock and each census, equal to 1 if the income is at the $\operatorname{cap}^{32}$ or zero if not.

\footnotetext{
30 The indigenous people of NZ.

31 The subject population is households in private occupied dwellings.

$32 \$ 100,000$ in 2001 and 2006, and \$150,000 in 2013 .
} 


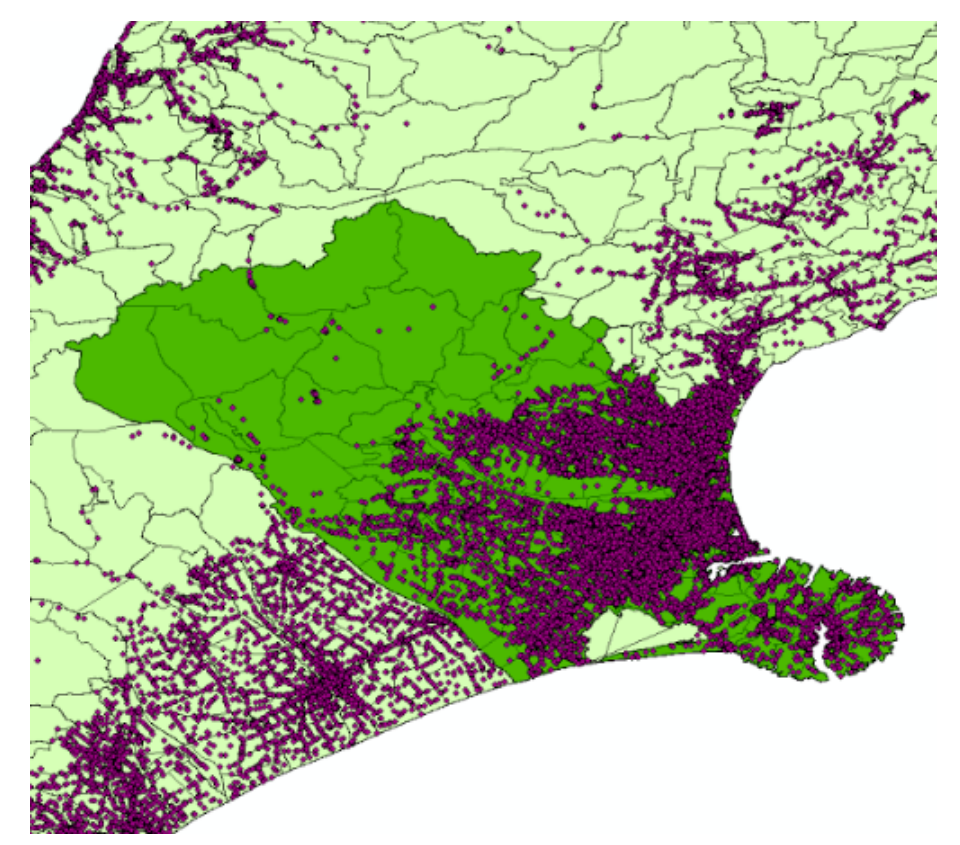

Map 1: Mapped properties with claims, zoomed to the Canterbury region.

This map is included as an example of the geo-locating process, and to help the reader visualise the data. Each purple circle represents a property (not to scale), and each light green shape behind it (forming the map of New Zealand) is a meshblock polygon.

\subsection{Combined Dataset}

Each property is matched to a meshblock ${ }^{33}$, which allows us to match the property-level EQC data to the mesh block-level socio-economic data collected from the Census. An example of this process is shown in Map 1. The data from this combined dataset is summarized in Table 1. In Canterbury, 94,722 properties have closed building claims with positive payouts relating to the 2010-11 sequence of earthquakes and contain all the necessary census information. ${ }^{34}$

As a first step in investigating the distributional implications of the EQC cover, in Figure 1, I graph the payout data by property decile and income decile for all the claims arising out of the Canterbury Earthquake Series dataset. In the figure, as the property decile increases, the average total dwelling payout for the decile increases as well, with a sharpest increase for the tenth decile. This pattern is repeated in the panel on the right where I use median household income deciles.

\footnotetext{
33 Using the "spatial join" toolbox in ArcGIS - see the Appendix for a detailed explanation of this matching. ${ }^{34}$ Of 5590 in the wider Canterbury region.
} 


\begin{tabular}{lllll}
\hline VARIABLES & $\begin{array}{l}(1) \\
\text { mean }\end{array}$ & $\begin{array}{l}(2) \\
\text { sd }\end{array}$ & $\begin{array}{l}(3) \\
\text { min }\end{array}$ & $\begin{array}{l}(4) \\
\text { max }\end{array}$ \\
\hline Total Dwelling Payout & & & & \\
Total Assessed Building Repair Costs & 45,755 & 58,202 & 0 & 358,381 \\
Dwelling Adjusted Building Value '10 & 63,346 & 139,196 & 0 & $1.498 \mathrm{e}+07$ \\
Building Value '10 & 296,700 & 166,462 & 1,120 & $2.091 \mathrm{e}+07$ \\
Rural Meshblock & 319,810 & 239,501 & 43,844 & $2.091 \mathrm{e}+07$ \\
& 0.0718 & 0.258 & 0 & 1 \\
Median Household Income '01 & & & & \\
Median Household Income '06 & 40,964 & 15,413 & 7,500 & 100,000 \\
Proportion Tertiary Educated '06 & 52,059 & 18,180 & 5,800 & 100,000 \\
Proportion Not Homeowners '06 & 0.151 & 0.0983 & 0 & 0.625 \\
Proportion Māori '06 & 0.279 & 0.187 & 0 & 1 \\
Proportion Pasifika ‘06 & 0.0710 & 0.0583 & 0 & 0.571 \\
Proportion Born Overseas '06 & 0.0207 & 0.0379 & 0 & 0.478 \\
Mean Number of Household Members ‘06 & 0.187 & 0.0888 & 0 & 0.800 \\
Dif. in Med HH Income '01-'06 & 2.550 & 0.389 & 1 & 5 \\
& 11,095 & 11,569 & $-61,700$ & 79,200 \\
\hline
\end{tabular}

Table 1: Summary Statistics

This table contains the summary statistics of the 94,722 properties with closed building claims associated with the Canterbury Earthquake series. Total Dwelling Payout is the sum of all managed repair costs or cash settlements received for a property, divided by the number of dwellings on that property. Total Assessed Building Repair costs are the sum of all actual assessments of repairs for the property - usually an assessment is made for each major event. Dwelling Adjusted Building Value '10 is the EQC supplied value of the building (Building Value '10) as at mid-2010 divided by the number of dwellings on the property. These cover 9,533 meshblocks, the smallest unit for which Statistics New Zealand collects data. Rural meshblcok is an indicator variable equal to one if Statistics New Zealand classifies the area as rural. Each of the other variables are meshblock level Census variables. All are self-reported in the 2001 or 2006 Census, except Dif. in Med HH Income '01-'06, which is the difference between the 2006 and 2001 values of Median Household Income in the meshblock. 

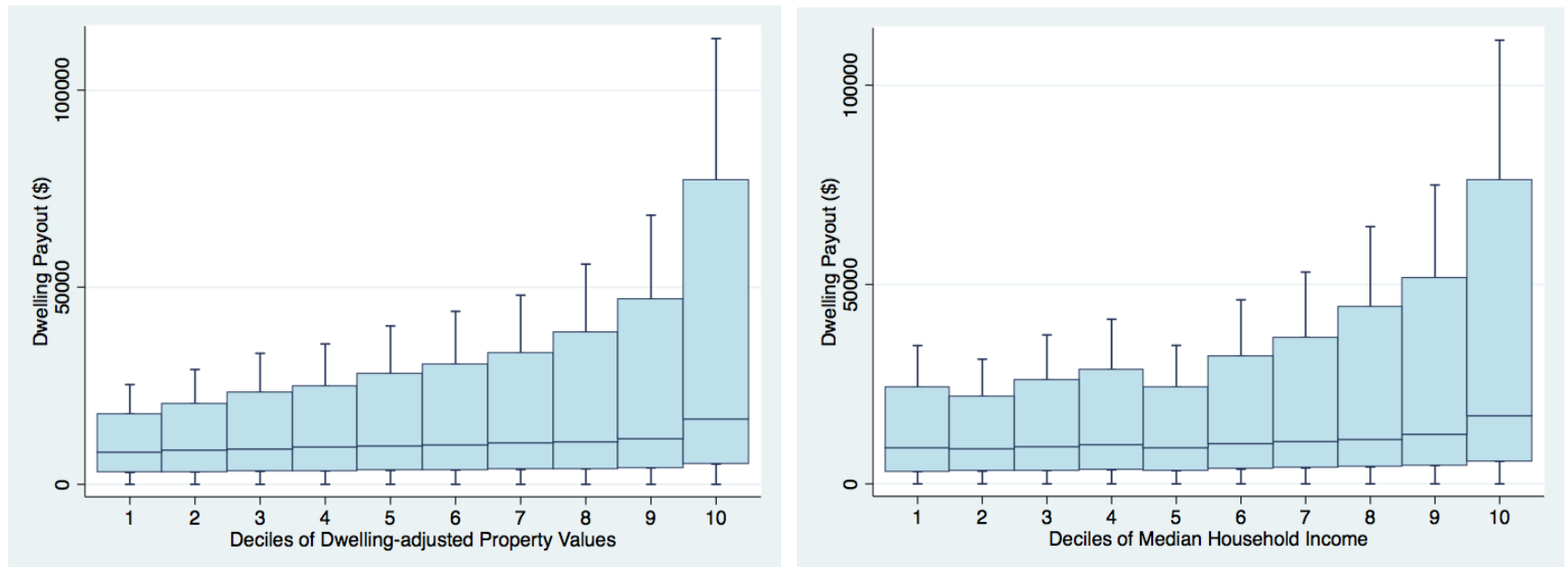

Figure 1: Distribution of Dwelling Payouts by Property Value and Income deciles.

The dataset includes information on all claims made to the NZ EQC related to insured damages following the earthquakes in the Canterbury region for events from 2010-09-04 to 2012-02-11. Distribution of payouts per property adjusted by number of dwellings insured by deciles of either dwelling adjusted modelled building value as at mid-2010, or meshblock level median household income as at 2006. Whiskers indicate 0.5 times the IQR, to better show the median values (version with standard whiskers in appendix).

In the boxplots, the middle line indicates the median, the shaded box indicates the inner-quartile range (IQR), and "whiskers" indicate 0.5 times the IQR. A notable observation is the increase in the spread of the total payout per dwelling as the deciles increase. This reflects higher-value properties requiring higher cost of repairs. ${ }^{35}$

\footnotetext{
35 It is worth reminding the reader here that these only take into account the payouts from the public insurer, and it is likely that significantly damaged homes would have also received repair payouts from their private insurance company. However, these are paid for with additional premiums.
} 


\section{Methodology}

Given the effectively flat premiums paid for EQC cover by homeowners, I expect some redistribution to occur. I hypothesise two different mechanisms for the regressivity for which I have already found some evidence (see Figure 1). These are:

1. Wealthier households may live in riskier areas (such as on hill-sides or by the water) leading to a higher likelihood of natural hazard exposure, and so a higher likelihood of damage occurring.

2. The $\$ 100,000$ capped amount on building payments per event is likely to be required more for wealthier homes, due to these homes having the capacity to incur more damage. Given the higher value of each component of the home, all else constant, high value homes may incur more damage.

The first mechanism is frequently mentioned as a plausible one for flooding damages, both from storm surges that hit coastal properties and from riverine floods that hit properties on river banks. It is therefore less interesting, and also probably less relevant for earthquakes whose exact location and seismic wave propagation are more random and less oriented with obvious external characteristics of housing. In the case of the Canterbury earthquakes, the 22/2/2011 earthquake's epicentre was located to the South-East of the city, and in general the Eastern suburbs are less wealthy while the North-Western suburbs, further away from the epicentre of the earthquake, have the higher value properties and higher income households.

The second mechanism is therefore the focus of analysis of the Canterbury experience. The hypothesis examined is that wealthier homeowners own properties that are likely to be costlier to repair up to replacement value than their less well-off counterparts. For example, a larger house simply has more interior floors that may crack, and these floors may have been made from more expensive materials. Naturally, there are also possible mechanisms that can lead to the opposite outcome: perhaps newer or better-maintained houses are less vulnerable to earthquakes. Ultimately, it is an empirical question whether the value of housing is correlated with the amount of damages. I first look at whether higher-value homes in Canterbury sustained higher damages from the Canterbury Earthquake Series. Wealthier homeowners are in this 
case identified by the value of the home, and the approximated socioeconomic status of the residents in the respective meshblock. ${ }^{36}$

To analyse this, I regress the assessed repair cost on the most recent valuation of the property, as well as a number of indicators of the socio-economic level of residents.

$$
Y_{i}=\alpha+\beta_{1} \text { PropertyValue }_{i}+\beta_{2} \text { MedHHIncome }_{i}+\gamma X_{i}+\varepsilon_{i}
$$

where $Y_{i}=$ TotalRepair $_{i}$ is the sum of all assessed repair costs made for property $i$ for claims related to earthquake events during the specified location (Canterbury) and time period (2010-11). The error term, $\varepsilon_{i}$, is clustered at the meshblock level to account for some of the explanatory variables only varying at this aggregate level. I estimate this with heteroscedastic and cluster robust standard errors (Cameron \& Miller, 2015). ${ }^{37}$

In a second specification that better captures the regressivity of the EQC scheme as it is currently structured, the dependent (LHS) variable is the total payout on a property $Y_{i}=$ TotalPayout $_{i}$, regressed against the same covariates, including the most recent valuation of the property and a number of control variables at the meshblock level. Several alternate specifications are presented to test the robustness of the results and to attempt to identify areas of variation that may require further analysis.

Given my focus on the distributional impact of EQ Cover, I also perform quantile regression on the Canterbury dataset, as below:

$$
Y_{i}=\alpha+\beta_{1} \text { PropertyValue }_{i}+\beta_{2} \text { MedHHIncome }_{i}+\gamma X_{i}+\varepsilon_{i}
$$

For a more in-depth discussion of quantile regression, see the Appendix.

\footnotetext{
36 Due to the nature of the available data, I cannot identify if one homeowner owns multiple properties. Given this missing indicator of the particularly wealthy the results are likely to be conservative. Further, although the property valuation speaks somewhat directly to the wealth of the homeowner, the census data relates to the residents of these meshblocks, rather than the homeowners. Thus, for example, a "slum lord" who owned a number of cheaper properties in low socio-economic areas would also not be identified properly. The majority of houses are owner-occupied (67\% of the 2006 Census residential dwellings), which somewhat mitigates this problem. However, perhaps future research with more specific data could investigate the implications of this.

${ }^{37}$ I also perform this analysis at the claim level (rather than summing all claims for a single property). These results are very similar, and are available upon request.
} 


\section{Results and Discussion}

The first results from the Canterbury analysis are shown in Table 2. In columns 1-3, Total Actual Assessed Repair Costs is the dependent variable, and in columns 4-6 Adjusted Total Dwelling Payout is used. Columns 1 and 4 show the most comprehensive specifications. The first clear result is that the coefficients of interest (those on property value or median household income) are always positive and statistically significant at the $1 \%$ level (non-zero). Their magnitude is such that for every NZ\$1000 of higher dwelling value, there was an approximate $\$ 57.70$ increase in Total Actual Assessed Repair cost, holding other factors constant, including median household income in the meshblock. Further, for every NZ\$1000 of higher building value, on average approximately $\$ 25.70$ more has been paid out from EQC, holding all else constant. Also, the association of higher values in these wealth/income indicators is over twice as large for assessed repair costs than for the actual EQC payouts.

The effects of the meshblock-level explanatory variables are qualitatively the same for both dependent variables, and consistently affect the dependent variables in the expected directions. The growth in median HH income (2001 to 2006) has a negative effect when statistically significant; so that the "newer" the wealth in the area, the lower the assessed damage and EQC payout. It has been widely suggested that because of the bureaucratic complexity of the insurance system, more educated claimants find it easier to navigate the system and successfully claim for damages. This hypothesis justifies the tertiary education measure included as an explanatory variable. As hypothesized, the coefficient is positive and statistically significant. It has also been suggested that homeowners that live in the house are more likely to negotiate with the insurer more extensively, as the damage is closer to home. This variable is statistically significant and negative as hypothesized. Another possible factor is the number of household members. Larger household size, another imperfect proxy for socio-economic status, is also negative and statistically significant as hypothesized.

I also include a number of ethnicity variables at the meshblock level. The Proportion Māori and Proportion Pasifika are included to check if the scheme is having an adverse effect on these minorities of particular importance to New Zealand. In New Zealand, both ethnicities are correlated with lower income, on average, though the Pasifika population (those originating from other Pacific Islands) are generally more disadvantaged with a significant proportion using English as a second language. However, after controlling for income, education and family size, these ethnicities are 
statistically identified with positive effects on both damages and payouts. Finally, I also include the proportion of the population born overseas as tabulated in the 2006 census, in case the claim process is more difficult for this group to navigate because of language barriers, fewer local social networks, lack of communication channels with damage assessors about deadlines, etc. The assessed repair costs are not significantly affected by this measure. However, there does appear to be a negative effect on total dwelling payouts. Finally, if the property is in a rural meshblock, the analysis shows negative effects on both damages and total payouts, likely because most rural meshblocks were further away from the quake's epicentre.

In Table 3 the results of progressively removing some of the explanatory variables are presented, to establish the robustness of results. In column (1) (identical to column (4) in Table 3) all the explanatory variables are statistically significantly different from zero at the $1 \%$ level, excepting the proportion born overseas.

I first remove the difference in median household income from 2001-2006, as this has a more tenuous theoretical effect on payouts, but is directly correlated with the coefficient of interest. This specification is presented in column (2). It results in a decrease in the effect of 2006 Median Household Income, and has a small positive effect on the coefficient on Building Value.

In column (3) I remove the least statistically significant variable: the proportion of the meshblock born overseas. The coefficient on median household income increases slightly and becomes marginally more precise, while the effect of building value remains unchanged.

Dropping the proportion tertiary educated in column (4) leads to a sharp increase in the effect of median household income, corroborating the observation that education and income are generally positively correlated, and showing that without controlling for education, the neighbourhood income effect would be overestimated. This also leads to a slight increase in the effect of building value, and interestingly, also decreases the absolute values of the coefficients on the ethnicity controls.

In column (5) ethnicity and household member controls are removed, bringing building value down marginally, median 06 household income down sharply, and removing all statistical significance of the proportion not homeowners. Removing this last proportion in column (6) completes the robustness checks, with negligible effects on the coefficients of interest. 
The primary results remained relatively robust throughout these checks. Tertiary education and changes in household income appear the most correlated with median household income, as to be expected. The proportion not homeowners appears to affect the dependent variable only through the other controls. There is clearly some cultural effect at work, as controlling for income and education increases the absolute value of the coefficients on ethnicity controls.

There are disadvantages to OLS regression compared to other specifications. Specifically, the OLS gives the effect on the mean. The mean, in a dataset like the one here, can be somewhat misleading. Further, the mean for an analysis of the distributional implication is perhaps less informative than some other measure which can better differentiate the affluent from the disadvantaged. So, I next redo my analysis of the Canterbury case, taking into account these concerns by performing a quantile regression. Results from this analysis can be seen in Table 4, where I report the effect on the $25^{\text {th }}, 50^{\text {th }}$ and $75^{\text {th }}$ quantiles, and compare to the effect on the mean 


\section{Dwelling adjusted Building Value '10}

\section{Median Household Income ‘06}

Dif. in Med HH Income '01-’06

Proportion Tertiary Educated ‘06

Proportion Not Homeowners ‘06

Mean Number of Household Members ‘06

Proportion Māori ‘06

Proportion Pasifika '06

Proportion Born Overseas ‘06

Rural Meshblock

Constant

Observations

R-squared

$\begin{array}{cc}\mathbf{0 . 0 5 7 7} * * * & 0.0671^{* * *} \\ (\mathbf{0 . 0 1 4 5 )} & (0.0163)\end{array}$

$(0.0145)$

$1.297^{* * *}$

(0.149)

$-0.839 * * * 161)$
$(0.161$

$93,461^{* * *}$

$(18,081)$

$-23,626^{* *}$

$(9,344)$

$-32,364 * * *$

$(4,100)$

$102,156^{* * *}$

$(27,231)$

$110,083^{* * *}$

$(37,144)$

$-22,657$

$(16,017)$

$-46,007^{* * *}$

$(2,733)$

61,067***

$(10,575)$

$(0.0163)$

94,723

\section{$-0.0790$}

(0.132)

$178,205^{* * *}$

$(17,336)$

$-55,219 * * *$

$(9,579)$

$-12,728^{* * *}$

$(3,599)$

65,041**

$(27,339)$

81,959**

$(37,533)$

$-46,174^{* * *}$

$(16,277)$

$-45,428 * * *$

$(2,721)$

$70,917^{* * *}$

$(10,855)$

$1.404^{* * *}$
$(0.147)$
$-0.896^{* * *}$
$(0.161)$
$95,614^{* * *}$
$(18,144)$
$-25,703^{* * *}$
$(9,316)$
$-31,872^{* * *}$
$(4,101)$
$92,382^{* * *}$
$(27,055)$
$105,593^{* * *}$
$(37,110)$
$-22,376$
$(15,999)$
$-44,539^{* * *}$
$(2,699)$
$72,808^{* * *}$
$(10,137)$

94,799
0.036

\section{$0.0257^{* * *}$ \\ $0.0304^{* * *}$}

(0.00653)

$0.662^{* * *}$

(0.0713)

$-0.364^{* * *}$

(0.0775)

77,588***

$(9,370)$

$-14,901^{* * *}$

$(4,835)$

$(2,084)$

84,528***

$(15,261)$

79,400 ***

$(20,728)$

$-19,178^{* *}$

$(8,899)$

$-28,920$ ***

$(1,394)$

$38,727^{* * *}$

$(5,427)$

(0.00747)

94,723

0.079
$0.710^{* * *}$

(0.0707)

0.0235

$-0.390 * * *$

(0.0655) (0.0776)

$120,855^{* * *} \quad 78,459^{* * *}$

$(8,856) \quad(9,388)$

$-31,031^{* * *} \quad-15,852^{* * *}$

$(4,824) \quad(4,810)$

$-5,869 * * * \quad-15,671^{* * *}$

$(1,915) \quad(2,083)$

65,579*** 80,172***

$(15,275) \quad(15,194)$

$65,041^{* * *} \quad 77,281^{* * *}$

$(20,948) \quad(20,705)$

$-31,185^{* * *} \quad-19,023^{* *}$

$(9,037) \quad(8,879)$

$-28,624^{* * *} \quad-28,259^{* * *}$

$(1,392) \quad(1,384)$

$43,757^{* * *} \quad 43,941^{* * *}$

$(5,536) \quad(5,243)$

$94,723 \quad 94,799$

$0.066 \quad 0.074$

Robust standard errors in parentheses. ${ }^{* *} \mathrm{p}<0.01, * * \mathrm{p}<0.05,{ }^{*} \mathrm{p}<0.1$. This table contains results from OLS regressions with meshblock level clustered standard errors. The dataset includes information on all claims made to the NZ EQC related to insured damages following the earthquakes in the Canterbury region for events from 2010-09-04 to 2012-02-11. The dataset is at the property level and excludes zero value claims (those which did not receive EQC funded repairs). The raw claims and portfolio data is confidential because of privacy concerns. The other explanatory variables are all gathered from publicly available Census tabulation from StatisticsNZ. These are meshblock level variables as collected from the 2006 (and for Median Household Income, 2001) Census.38

38 The reader will naturally note the low R-squared values. Note however that this research did not set out to accurately predict damages or payouts, but to identify variations correlated with socioeconomic characteristics in order to determine the distributional implications of the scheme. A low R-squared is therefore not of concern in this context. 


\begin{tabular}{|c|c|c|c|c|c|c|}
\hline \multirow[b]{2}{*}{ VARIABLES } & (1) & (2) & (3) & $(4)$ & (5) & (6) \\
\hline & \multicolumn{6}{|c|}{ Total Dwelling Payout } \\
\hline Dwelling adjusted Building Value '10 & $\begin{array}{l}0.0257^{* * *} \\
(0.00653)\end{array}$ & $\begin{array}{l}0.0269 * * * \\
(0.00678)\end{array}$ & $\begin{array}{l}0.0269 * * * \\
(0.00678)\end{array}$ & $\begin{array}{l}0.0282^{* * *} \\
(0.00700)\end{array}$ & $\begin{array}{l}0.0264^{* * *} \\
(0.00647)\end{array}$ & $\begin{array}{l}0.0264^{* * *} \\
(0.00644)\end{array}$ \\
\hline Median Household Income ‘06 & $\begin{array}{l}0.662 * * * \\
(0.0713)\end{array}$ & $\begin{array}{l}0.473^{* * *} \\
(0.0591)\end{array}$ & $\begin{array}{l}0.491^{* * *} \\
(0.0582)\end{array}$ & $\begin{array}{l}0.729 * * * \\
(0.0553)\end{array}$ & $\begin{array}{l}0.507^{* * *} \\
(0.0502)\end{array}$ & $\begin{array}{l}0.504^{* * *} \\
(0.0450)\end{array}$ \\
\hline Dif. in Med HH Income '01-'06 & $\begin{array}{c}-0.364^{* * *} \\
(0.0775)\end{array}$ & & & & & \\
\hline Proportion Tertiary Educated ‘06 & $\begin{array}{c}77,588^{* * * *} \\
(9,370)\end{array}$ & $\begin{array}{c}85,462^{* * *} \\
(9,353)\end{array}$ & $\begin{array}{c}77,979 * * * \\
(8,549)\end{array}$ & & & \\
\hline Proportion Not Homeowners '06 & $\begin{array}{c}-14,901^{* * *} \\
(4,835)\end{array}$ & $\begin{array}{c}-18,594^{* * *} \\
(4,858)\end{array}$ & $\begin{array}{c}-21,511^{* * *} \\
(4,540)\end{array}$ & $\begin{array}{c}-8,876^{* *} \\
(4,428)\end{array}$ & $\begin{array}{c}512.2 \\
(4,317)\end{array}$ & \\
\hline Mean Number of Household Members '06 & $\begin{array}{c}-15,895^{* * *} \\
(2,084)\end{array}$ & $\begin{array}{c}-14,299 * * * \\
(2,087)\end{array}$ & $\begin{array}{c}-15,102^{* * *} \\
(2,041)\end{array}$ & $\begin{array}{c}-17,301^{* * *} \\
(2,066)\end{array}$ & & \\
\hline Proportion Born Overseas ‘06 & $\begin{array}{c}-19,178^{* *} \\
(8,899)\end{array}$ & $\begin{array}{c}-20,625^{* *} \\
(8,933)\end{array}$ & & & & \\
\hline Proportion Māori ‘06 & $\begin{array}{c}84,528^{* * *} \\
(15,261)\end{array}$ & $\begin{array}{c}80,825^{* * *} \\
(15,262)\end{array}$ & $\begin{array}{c}89,274^{* * *} \\
(14,413)\end{array}$ & $\begin{array}{c}60,879 * * * \\
(14,018)\end{array}$ & & \\
\hline Proportion Pasifika ‘06 & $\begin{array}{c}79,400^{* * * *} \\
(20,728)\end{array}$ & $\begin{array}{c}75,247^{* * *} \\
(20,814)\end{array}$ & $\begin{array}{c}71,703^{* * *} \\
(20,799)\end{array}$ & $\begin{array}{l}52,096^{* *} \\
(20,778)\end{array}$ & & \\
\hline Rural Meshblock & $\begin{array}{c}-28,920^{* * *} \\
(1,394)\end{array}$ & $\begin{array}{c}-28,863^{* * *} \\
(1,399)\end{array}$ & $\begin{array}{c}-28,077^{* * *} \\
(1,379)\end{array}$ & $\begin{array}{c}-31,257^{* * *} \\
(1,350)\end{array}$ & $\begin{array}{c}-34,118^{* * *} \\
(1,329)\end{array}$ & $\begin{array}{c}-34,147^{* * *} \\
(1,249)\end{array}$ \\
\hline Constant & $\begin{array}{c}38,727^{* * *} \\
(5,427)\end{array}$ & $\begin{array}{c}40,524^{* * *} \\
(5,455)\end{array}$ & $\begin{array}{c}39,145^{* * *} \\
(5,467)\end{array}$ & $\begin{array}{c}42,908^{* * *} \\
(5,514)\end{array}$ & $\begin{array}{c}13,849^{* * *} \\
(3,847)\end{array}$ & $\begin{array}{c}14,133^{* * *} \\
(2,555)\end{array}$ \\
\hline $\begin{array}{l}\text { Observations } \\
\text { R-squared }\end{array}$ & $\begin{array}{c}94,723 \\
0.079\end{array}$ & $\begin{array}{c}94,723 \\
0.076\end{array}$ & $\begin{array}{c}94,723 \\
0.075\end{array}$ & $\begin{array}{c}94,723 \\
0.064\end{array}$ & $\begin{array}{c}94,725 \\
0.053\end{array}$ & $\begin{array}{c}94,725 \\
0.053\end{array}$ \\
\hline
\end{tabular}

Robust standard errors in parentheses. ${ }^{* * *} \mathrm{p}<0.01,{ }^{* *} \mathrm{p}<0.05,{ }^{*} \mathrm{p}<0.1$. This table contains results from OLS regressions with meshblock level clustered standard errors. The dataset includes information on claims made to the New Zealand Earthquake Commission related to Earthquakes or Fires following Earthquakes in the Canterbury region of New Zealand for events from 2010-09-04 to 2012-02-11. The dataset is at the property level and excludes unfunded claims. Raw data

confidential. Data source: EQC. Total dwelling payout is an aggregate variable including both any cash settlement made to the property and any payout for managed repairs, divided by the number of dwellings insured on that property. Adjusted Building Value 10 is the building value for the portfolio, divided by the number of dwellings insured on the property. The other explanatory variables are all gathered from publicly available Census data from Statistics New Zealand. These are meshblock level variables as collected in the 2006 (and for Median Household Income, 2001) Census. 


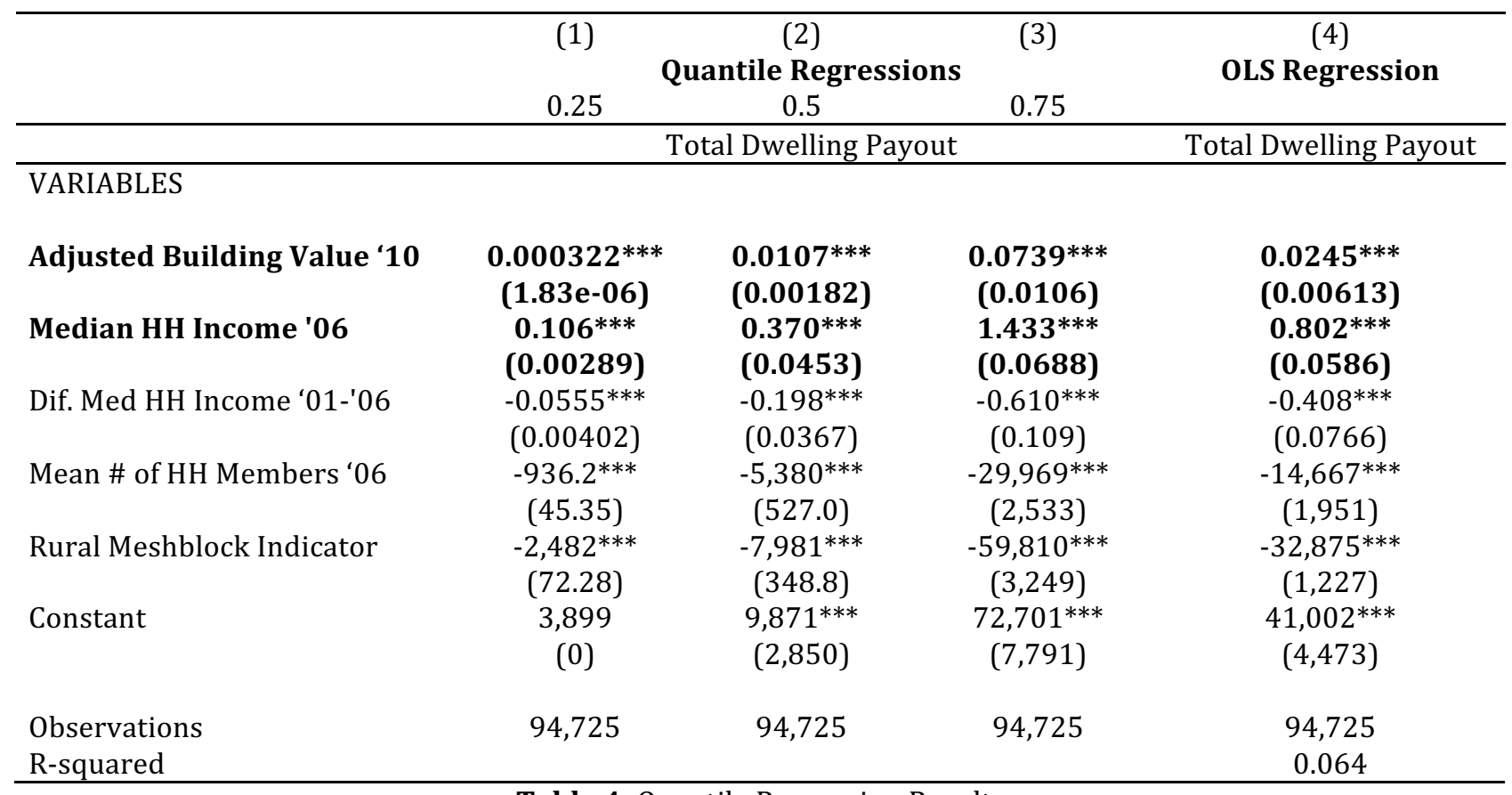

Table 4: Quantile Regression Results

Robust standard errors in parentheses. ${ }^{* *} \mathrm{p}<0.01,{ }^{* *} \mathrm{p}<0.05,{ }^{*} \mathrm{p}<0.1$ This table contains results from quantile regressions with meshblock level clustered standard errors. The dataset includes information on all claims made to the NZ EQC related to insured damages following the earthquakes in the Canterbury region for events from 2010-09-04 to 2012-02-11. The dataset is at the property level and excludes zero value claims (those which did not receive EQC funded repairs). The raw claims and portfolio data is confidential because of privacy concerns. The other explanatory variables are all gathered from publicly available Census tabulation from StatisticsNZ. These are meshblock level variables as collected in the 2006 (and for Median Household Income, 2001) Census.

Columns 1-3 of Table 5 contain coefficients from regressions at different quantiles. In Column 1 are those pertaining to the $25^{\text {th }}$ percentile. As the reader can see, the coefficients of interest are rather small but significant. On average, with a thousand-dollar increase in Adjusted Building Value, I would expect the $25^{\text {th }}$ percentile of Total Dwelling Payout to increase by only 30c, all else equal. However, with a thousand-dollar increase in Median Household Income there would be on average a $\$ 100$ increase in the $25^{\text {th }}$ percentile of Total Dwelling Payout. In Column 2 see the effect on the median of Total Dwelling Payout, which are significantly higher than those for the $25^{\text {th }}$ percentile, and in Column 3 the effect on the $75^{\text {th }}$ percentile, which are higher again. Interestingly the coefficients of interest by OLS regression sit between the median and $75^{\text {th }}$ quantile results. ${ }^{39}$

\footnotetext{
${ }^{39}$ I should note here that quantile coefficients tell us about effects on the distribution, not on individuals.
} 


\section{Looking forward and abroad}

\subsection{A solution to EQC's regressivity problem}

A fix to the unfortunate regressivity of the NZ disaster insurance system is remarkably simple; rather than paying a flat premium per year, homeowners could be required to pay a set percentage of total private sum insured. This would reflect that homes with a larger sum insured are more likely to claim larger amounts, even of the $\$ 100,000$ per dwelling, as shown in the analysis thus far. This modification would correct the regressivity issue.

To test this suggestion, I perform a numerical simulation on the Canterbury dataset. I simulate the premiums using the percentages adopted by EQC, but applied to the Dwellingadjusted building value as opposed to the first $\$ 100,000$ of these. This would move the scheme towards a more risk-based (as opposed to flat) premium structure.

First the suggested premiums for each property (by EQC Property Group) are created as $0.0005 \times$ (Dwelling-adjusted building value as at mid-2010). Then, the same process is used but substituting 0.0005 for first 0.0015 and then 0.002 . To explore what this would have meant for Canterbury building claimants, I build the distribution of these suggested premiums within each decile of dwelling-adjusted building values. As shown in Figure 2 below, annual premiums would have been slightly higher for those homeowners living in wealthier areas. However, they are by no means unaffordable.

Using the $0.0005 \%$ measure, for the first six deciles of properties by Dwelling-adjusted Property Values, suggested premiums per year would actually likely be lower than the current $\$ 150$ per annum, and for no one does the suggested premium go above $\$ 400$ per annum. A homeowner whose home was valued at $\$ 300,000$ (and insured to that level) would pay $\$ 150$ per year, whereas a homeowner whose home was valued at $\$ 1,000,000$ would pay $\$ 500$ per year. With the $0.0015 \%$ or $0.002 \%$ measures, the vast majority of homeowners would still pay less than $\$ 1000$ per year.

With these 94722 homes, under the original premium structure EQC would have raised $4,736,100$ in one year if all were single dwelling homes. With the suggested premiums, EQC would have raised $14,100,000$ with the $5 \%$ measure, $42,200,000$ with the $15 \%$ or $56,200,000$ with the $20 \%$. Thus, the premium change would have other benefits for EQC. 

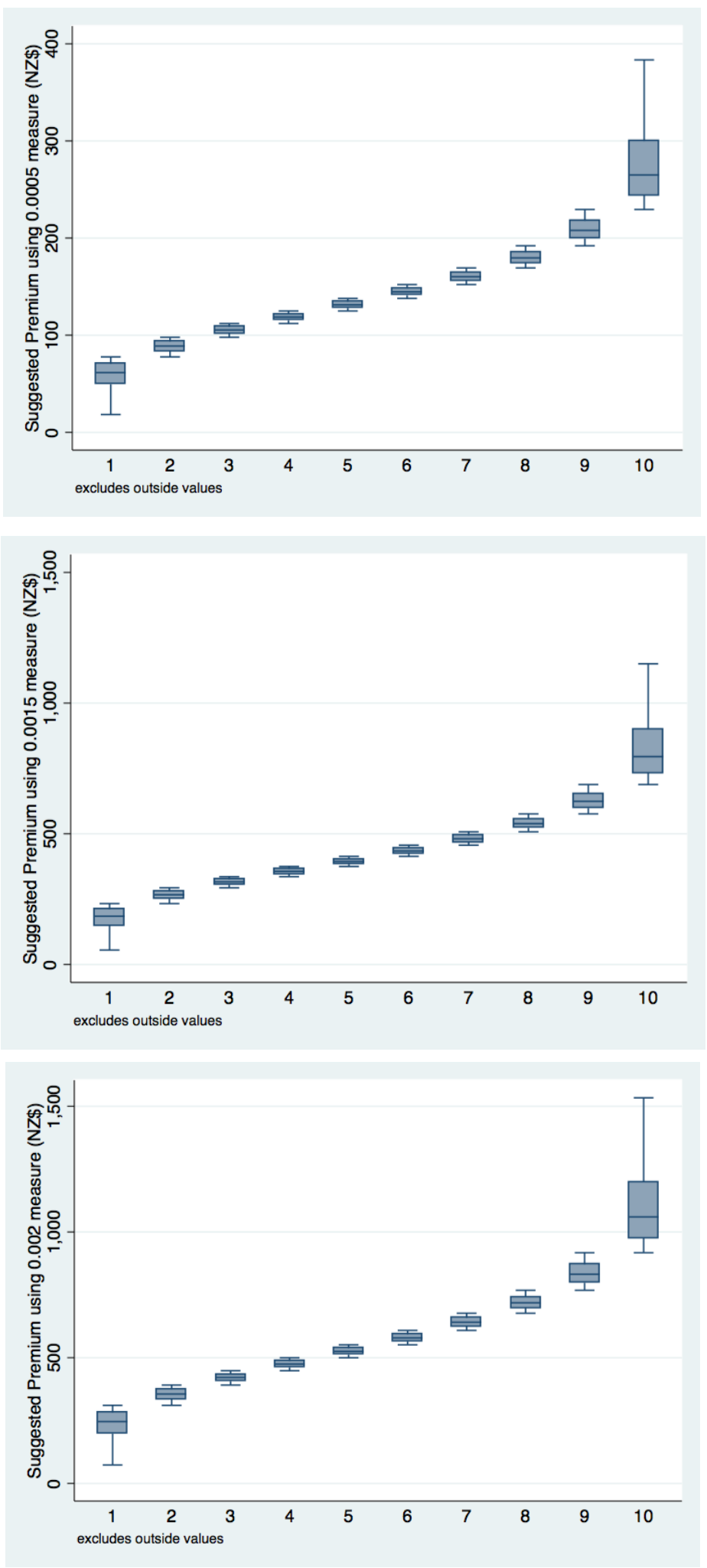

Figure 2: Distribution of suggested premiums.

This figure shows the distribution of suggested premiums. The first shows the distribution of premiums as 0.0005 times the dwelling-adjusted building value (pre quake), the second using 0.0015 and the third using 0.002 . The building values are as at mid-2010, and adjusted by the number of dwellings recorded. This figure also uses only the building claimants from the Canterbury 2010-2011 earthquake series. Data supplied by EQC, and confidential. Dollars are NZ\$. 

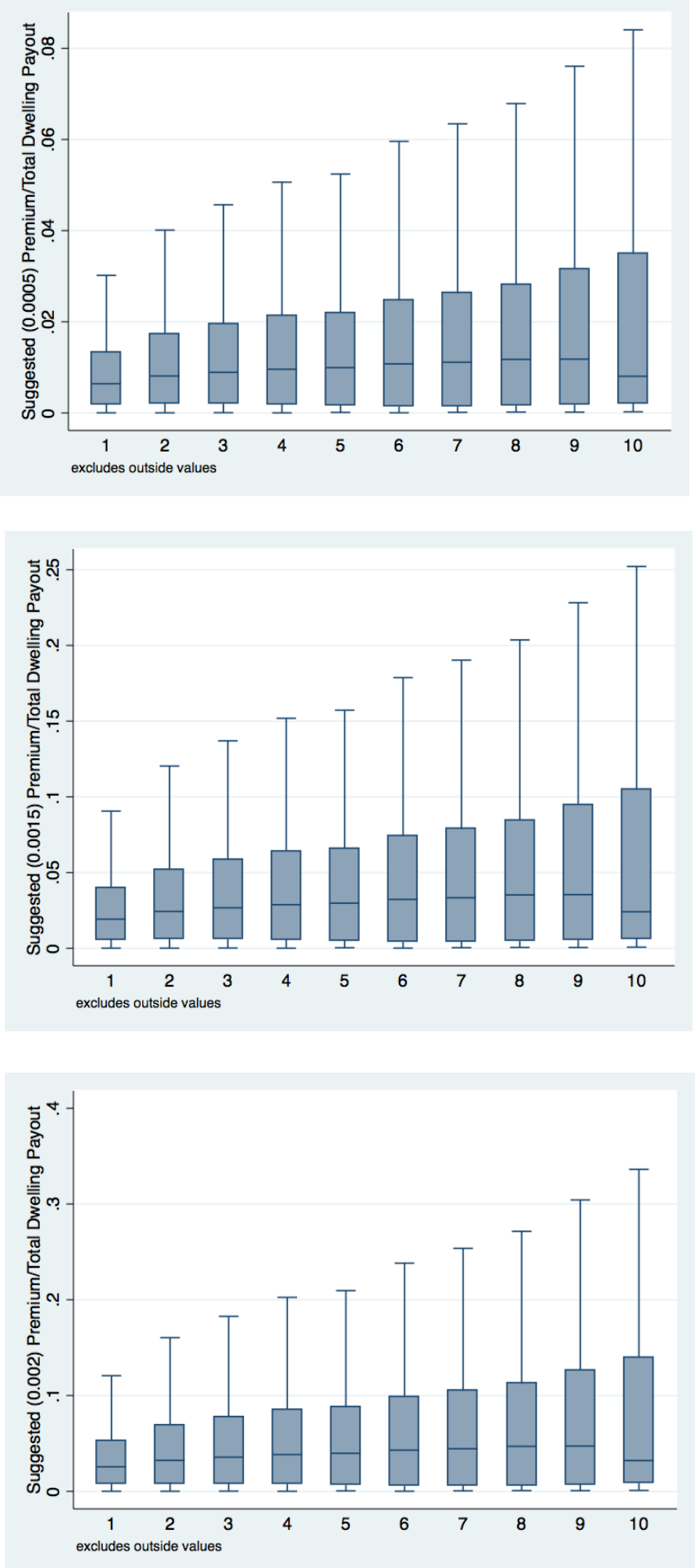

Figure 3: Premium to Payout Ratio for suggested premiums, by Building Value Decile

This figure shows the distribution of Suggested Premium/Total Payout, where in panel 1 the suggested premium is calculated as 0.0005 times the dwelling-adjusted building value (pre quake), the second using 0.0015 and the third using 0.002 . The building values are as at mid-2010. This figure also uses only the building claimants from the Canterbury 2010-2011 earthquake series. Data supplied by EQC, and confidential. Dollars are NZ\$. 
The hope with this progressive premium structure is that the ratio of premium to EQC payout becomes constant across deciles. In Figure 3 below, these ratios of suggested premiums against actual payouts (per dwelling), are graphed in standard box and whisker plots by building value decile. The median ratio for each is relatively flat across deciles, supporting this as a possible fix to the regressivity issue. The suggested premium structure could be adjusted to make it more constant. Alternate graphs by Median Household Income decile are included in the Appendix, as are those showing the flat structure as it operates currently.

Any of the three suggested options of premium structure would make EQC's residential building cover scheme significantly less regressive. The choice of premium structure (using $0.0005,0.0015$ or 0.002 ) would depend on the requirements for income raised per year and the capability of homeowners at the lower end of the spectrum to afford increased premiums. The 0.0005 measure reduces regressivity, increases EQC revenue per year, and does not increase annual premiums for homeowners of the lowest decile of valued homes. This measure is therefore preferred by the author. 


\subsection{International implications of this research}

There are a number of other schemes which, at first glance, may face similar problems to the New Zealand EQC distributional issue. Prior to this research, an extensive tabulation of public-private schemes and the characteristics that are likely to create distributional implications had not been undertaken. To fill this research gap, I note the basic characteristics of a number of schemes in Table 5 below. In particular, I note the components of the program that determine the degree of its regressivity: what perils are covered, who is covered, whether the indemnity is limited, and how premiums are set.

The analysis in earlier sections casts doubt on the egalitarianism of similar insurance systems. The systems most similar to New Zealand's are Romania, Spain, and Switzerland. Like EQC, PRAC (Romania), CCS (Spain) and KGV (Switzerland) are at least partially compulsory, with high market penetration as a result, and a flat method for premium setting. The most at risk of regressivity (and hence concerning) appears to be Switzerland, as there is no policy indemnity limit. Many other schemes have flat premium setting also; Austria, Denmark, France, Iceland, Norway, and the UK.

Non-compulsory systems include those in Austria, the UK, and the within state US programs. Of these, the Austrian system has flat premium setting (based on a percentage) and between $10-25 \%$ market penetration. With no policy indemnity limit, this system warrants some further scrutiny; if one quarter of the population are insured and a major disaster hits would they be subsidised by the Government? The UK system, Flood Re, is complex, and acts as more of a reinsurer than an insurer. Crucially, policy indemnity limits are at the discretion of the insurer, and premium setting is based on council tax banding, not risk. The within state insurance programs CEA, Citizens and TWIA are all non-compulsory but at least partially risk based. However, CEA does not have a policy indemnity limit, which is concerning if there are systematic differences between insurees which correlate with wealth.

There are many public or public-private schemes for residential housing natural disaster insurance worldwide. This research has particular implications for Romania, Spain, and Switzerland, where similar types of redistribution may be occurring. However, the concepts noted in this thesis (preference for risk based premiums in particular) also lead to concern for other schemes, especially those with flat pricing of premiums. 


\begin{tabular}{|c|c|c|c|c|c|c|}
\hline Country & System & Compulsory & $\begin{array}{c}\text { Market } \\
\text { penetration }\end{array}$ & $\begin{array}{c}\text { Policy indemnity } \\
\text { limit }\end{array}$ & $\begin{array}{l}\text { Premium- } \\
\text { setting }\end{array}$ & $\begin{array}{l}\text { Hazards } \\
\text { covered }\end{array}$ \\
\hline Austria & Obligatorium & No & $10-25 \%$ i & No & Flat (\%) & $\mathrm{NH}^{\mathrm{ii}}$ \\
\hline Belgium & WN & Partiallyiii & $>95 \%$ & Yes (nominal) & Risk based & $\mathrm{NH}$ \\
\hline Denmark & $\begin{array}{l}\text { Storm } \\
\text { Council }\end{array}$ & Partiallyiv & Unknown & No & $\begin{array}{c}\text { Flat } \\
\left(\text { nominalv }^{\text {) }}\right.\end{array}$ & Floodvi \\
\hline France & CatNat/CCR ${ }^{v i i}$ & Partiallyviii & $92 \%$ & $\begin{array}{l}\text { Yes (total insured } \\
\text { value) }\end{array}$ & Flat & $\mathrm{NH}$ \\
\hline Iceland & $\operatorname{ICI}^{\mathrm{ix}}$ & Yes & $100 \%$ & No & Flat $\left(\%^{x}\right)$ & $\mathrm{NH}^{\mathrm{xi}}$ \\
\hline Japan & $J E^{x i i}$ & Partially ${ }^{x i i i}$ & $20 \% / 46 \%$ xiv & $\begin{array}{l}\text { Yes (damage- } \\
\text { based) }\end{array}$ & Risk based & $\begin{array}{c}\text { EQ \& } \\
\text { related }\end{array}$ \\
\hline Norway & NNPPxv & Partiallyxvi & Unknown & No & $\begin{array}{c}\text { Flat } \\
\left(\% I^{x v i i}\right)\end{array}$ & $\mathrm{NH}^{x v i i i}$ \\
\hline $\mathbf{N Z}$ & $\mathrm{EQC}^{\mathrm{xix}}$ & Partially ${ }^{\mathrm{xx}}$ & $\sim 90 \%$ xxi & Yes (nominalxxii) & Flat & $\mathrm{NH}$ \\
\hline Romania & PRAC & Yes & $100 \%$ & Yes (nominal) & Flat ${ }^{\mathrm{xxiii}}$ & $\mathrm{NH}^{\mathrm{xxiv}}$ \\
\hline Spain & $\operatorname{CCS} x x v$ & Partiallyxxvi & $>80 \%$ & $\begin{array}{l}\text { Yes (total insured } \\
\text { value) }\end{array}$ & Flat & $\mathrm{NH}$ \\
\hline Switzerland & KGVs & Yes $^{\mathrm{xxvii}}$ & $>95 \%$ & No & Flat & $\mathrm{NH}$ \\
\hline Taiwan & TREIFxxviii & Partiallyxxix & $32.92 \% \mathrm{xxx}$ & Yes (replacement) & $\begin{array}{l}\text { Partially } \\
\text { risk } \\
\text { based }^{\mathrm{xxxi}}\end{array}$ & $\begin{array}{c}\text { EQ \& } \\
\text { related }^{\text {xxxii }}\end{array}$ \\
\hline Turkey & TCIPxxxiii & Partiallyxxxiv & $20 \%$ & Yes (nominal ${ }^{x x x v}$ ) & Risk based & $\begin{array}{c}\text { EQ \& } \\
\text { related }^{\text {xxxvi }}\end{array}$ \\
\hline UK & FloodRe $e^{\mathrm{xxxvii}}$ & No & $85 \%$ xxxviii & Varied $^{\mathrm{xxxix}}$ & Flat $^{\mathrm{xl}}$ & Flood \\
\hline USA & NFIPxli & Partiallyxlii & $\sim 50 \%$ xliii & Yes & $\begin{array}{l}\text { Partially } \\
\text { risk based }\end{array}$ & Flood \\
\hline $\begin{array}{c}\text { USA - } \\
\text { California }\end{array}$ & CEA $^{\text {xliv }}$ & No & $9.7 \%$ xlv & No & $\begin{array}{l}\text { Partially } \\
\text { risk } \\
\text { based }^{x l v i}\end{array}$ & $\begin{array}{l}\text { EQ \& } \\
\text { related }\end{array}$ \\
\hline $\begin{array}{l}\text { USA - } \\
\text { Florida }\end{array}$ & Citizens $^{x l v i i}$ & No & $8.5 \%$ & $\begin{array}{c}\text { Yes (total } \\
\text { insured/property } \\
\text { value) }\end{array}$ & $\begin{array}{l}\text { Partially } \\
\text { risk } \\
\text { based } \\
\text { xlviii }\end{array}$ & Windstorm \\
\hline USA - Texas & TWIA ${ }^{x l i x}$ & No & $57.2 \%{ }^{1}$ & $\begin{array}{l}\text { Yes }(\% \text { of } \\
\text { replacement } \\
\text { cost })^{\text {li }}\end{array}$ & $\begin{array}{l}\text { Partially } \\
\text { risk } \\
\text { based }\end{array}$ & Windstorm \\
\hline
\end{tabular}

Table 5: Public and Public-Private natural disaster insurance systems for personal property.

NH stands for Natural Hazards. Full notes too lengthy for this caption - in end-notes at end of section.

i CCS (2008) Gaschen et al. (1998) Bouwer et al. (2007)

ii Storms, hail, snow load, flooding, high ground water, EQs and subsidence.

iii With fire insurance

iv With fire insurance, and compulsory coastal flooding cover

v DKK 20 per year as of 2008 (CCS 2008).

vi Must be caused by seawater by a manifest rise in sea level from a cyclonic event. 
vii Caisse Centrale de Réassurance, see https://www.ccr.fr/activites/reassurances-et-fonds-publics/catastrophes-naturelles viii With property insurance

ix Iceland Natural disaster insurance, see https://www.vidlagatrygging.is/en/about-the-ici/

$\times 0.25$ per thousand of premium, collected by the fire insurance provider.

xi EQs, volcanic eruptions, avalanches, landslides and floods.

xii Japan Earthquake Reinsurance Co Ltd, see

http://www.mof.go.jp/english/financial_system/earthquake_insurance/outline_of_earthquake_insurance.html

xiii Loosely tied to fire insurance.

xiv Nguyen (2012), cites “Non-Life Insurance Rating Organization of Japan, http://www.nliro.or.jp/english/data.html”

xv Norwegian Natural Perils Pool.

xvi With fire insurance.

xvii 0.11 per thousand dollars of sum insured.

xviii Flood, storm and tempest, landslide, avalanche, EQ, and volcanic eruption.

xix Earthquake Commission, see http://www.eqc.govt.nz/

$x x$ With fire insurance

xxi EQC (2011)

xxii Properties are insured to replacement value, but the EQC payout per dwelling is capped at $100 \mathrm{~K}$, after which the private insurer makes up the difference.

xxiii 10 or 20 annually, determined by construction style.

xxiv EQ, flood, landslide and indirect losses caused by these perils.

xxv Consorcio de Compensación de Seguros

xxvi With property insurance

xxvii In all Swiss cantons, there is compulsory insurance for house owners: all Swiss house owners must insure against natural hazards and alpine risks such as storm, hail, flood, avalanche, snow loads, landslides and rock fall in addition to insurance against fire. (Schwarze et al. 2010)

xxviii Taiwan Residential Earthquake Insurance Fund, see http://www.treif.org.tw/eindex.aspx

xxix All residential fire insurance policies issued by insurers must automatically be extended to cover residential EQ risk.

xxx As of 2016, according to TREIF http://www.treif.org.tw/e_contents/B_financial/B1.aspx

xxxi Unified annual premium rate of NT\$1,459 (85\% pure risk and 15\% loading) (CCS 2008).

xxxii Fire, explosion, landslide, land subsidence, land movement, land rupture, tidal wave, surge and flood caused by

earthquake and resulting in total or constructive total loss (uninhabitable or whose repair cost is greater than $50 \%$ of the

rebuilding cost).

xxxiii Turkish National Natural disaster insurance Pool, see http://www.tcip.gov.tr/

xxxiv Compulsory for some dwellings.

xxxv Maximum sum insured NTL 110.000 (CCS 2008), otherwise policy sum insured determined by multiplying square meter costs with gross square meter area of dwelling.

xxxvi EQs and fire/explosion/landslides as a result of EQs.

xxxvii Flood RE, see http://www.floodre.co.uk/

xxxviii $85 \%$ of insurers participate in the pool. (Surminski 2017)

xxxix Appears to be at discretion of the insurer.

$\mathrm{xl}$ Based on council tax banding, not risk.

xli National Flood Insururance Program, see https://www.fema.gov/national-flood-insurance-program

xlii With federal mortgage in flood plain

xliii In the $1 / 100$ floodplain

xliv California Earthquake Authority, see https://www.earthquakeauthority.com/

xlv As of 2015 (Marshall 2017).

xlvi Factors include the insured value of the home, location, construction year, construction and foundation types, number of storeys, and the customer's coverage choices.

xlvii http://www.citizensfla.com/

xlviii Designed for "actuarial soundness" including some risk modelling (Kousky 2011)

xlix Texas Windstorm Insurance Association, see https://www.twia.org/

${ }^{1}$ McAneney et al. (2013)

li See https://www.twia.org/itv/

lii "Actuarially sound" but not strictly risk-based (McAneney et al. 2013). 


\section{Conclusion}

Private natural disaster insurance has not succeeded in adequately protecting private residential property, for numerous reasons discussed. Public intervention is thus a necessary measure to ensure protection for private homeowners in the event of a natural disaster.

Public natural disaster insurance has distributional consequences. When a scheme functions by collecting a fee from a large pool, to be paid out to a few under certain circumstances, of course there are transfers of wealth from some groups to others. Unfortunately, the mechanisms for wealth transfer in public disaster insurance are facilitating upward transfers; the poor partially subsidising the rich. This thesis involving a case study of the Canterbury Earthquake series in New Zealand clearly supports the hypothesis that more expensive homes incur higher damages in earthquakes. Economists are interested not only in which socioeconomic direction these transfers are flowing, but also in quantifying them. This analysis does so. It suggests that capped premiums have been incurring a risk transfer from homeowners of expensive homes to homeowners of lower-value homes, of the order of around $\$ 250$ more paid out by EQC per $\$ 10,000$ dollars of higher property value. Public natural disaster insurance is having a regressive effect in the New Zealand case.

I propose that the regressive effect would be counteracted by a simple shift from effectively flat premiums to a progressive system, with premiums calculated as a set percentage of the total private property sum insured (proxied by modelled dwelling value) as opposed to a percentage of the EQC sum insured, where payment structure and EQC payment cap remains the same. A simulation of a hypothetical pilot (using the Canterbury Earthquake series data) supports this approach.

Information on other public natural disaster schemes was also collected to identify those which may be similarly unfortunately regressive. Romania, Spain, and Switzerland are the most similar and thus are likely to face comparable issues.

Future research could extend this type of analysis to other public disaster insurance providers, to further investigate distributional implications in other styles of schemes. 


\section{Appendices}

\section{I - The difference between OLS regression and quantile regression ${ }^{40}$}

The conditional expectation function (CEF) for a dependent variable given covariates is the expectation, or population average, of the dependent variable with the covariates held constant. Mathematically, this can be expressed for a continuous dependent variable $Y_{i}$ with conditional density $f_{y}\left(t \mid X_{i}=x\right)$ at $Y_{i}=t$, as:

$$
E\left[Y_{i} \mid X_{i}=x\right]=\int t f_{y}\left(t \mid X_{i}=x\right) d t
$$

The law of iterated expectations says that an unconditional expectation can be written as the unconditional average of the CEF, ie:

$$
E\left[Y_{i}\right]=E\left\{E\left[Y_{i} \mid X_{i}\right]\right\}
$$

OLS regression is concerned with the distribution of the sample analog of

$$
\beta=\arg \min _{b} E\left[\left(Y_{i}-X_{i}^{\prime} b\right)^{2}\right]
$$

By the Linear CEF Theorem and the Bets Linear Predictor Theorem, it is the best predictor of the CEF in the class of all linear functions of $X_{i}$. Quantile regression starts with the conditional quantile function (CQF), rather than the CEF. The quantile regression function of a continuously distributed variable at quantile $\tau$ given a vector of regressors $X_{i}$ can be defined as below:

$$
Q_{\tau}\left(Y_{i} \mid X_{i}\right)=F_{y}^{-1}\left(\tau \mid X_{i}\right)
$$

where $F_{y}^{-1}\left(y \mid X_{i}\right)$ is the distribution function for $Y_{i}$ at $\mathrm{y}$, conditional on $X_{i}$. A random variable with less than well behaved density is more generally expressed as:

$$
Q_{\tau}\left(Y_{i} \mid X_{i}\right)=\inf \left\{y: F_{y}^{-1}\left(y \mid X_{i}\right) \geq \tau\right\}
$$

In the same spirit of the conditional expectation function, the CQF solves:

$$
Q_{\tau}\left(Y_{i} \mid X_{i}\right)=\operatorname{argmin}_{q(X)} E\left[\rho_{\tau}\left(Y_{i}-q\left(X_{i}\right)\right)\right]
$$

Quantile regression substitutes a linear model for $q\left(X_{i}\right)$, producing a tidy coefficient for each element of $X_{i}$, by:

$$
\beta_{\tau}=\operatorname{argmin}_{b} E\left[\rho_{\tau}\left(Y_{i}-X_{i}^{\prime} b\right)\right]
$$

The quantile regression estimator is the sample analog of the equation above.

\footnotetext{
${ }^{40}$ Angrist \& Pischke (2008)
} 


\section{II - Alternate graphic for Figure 1}

In Figure 1, I use slightly unusual box and whisker plots, with whiskers of 0.5 times the interquartile range. I chose this because the median values are difficult to see in the standard form. However, for transparency and completeness, I include the original box plots below in Figure 4, with whiskers the standard length of 1.5 times the IQR.
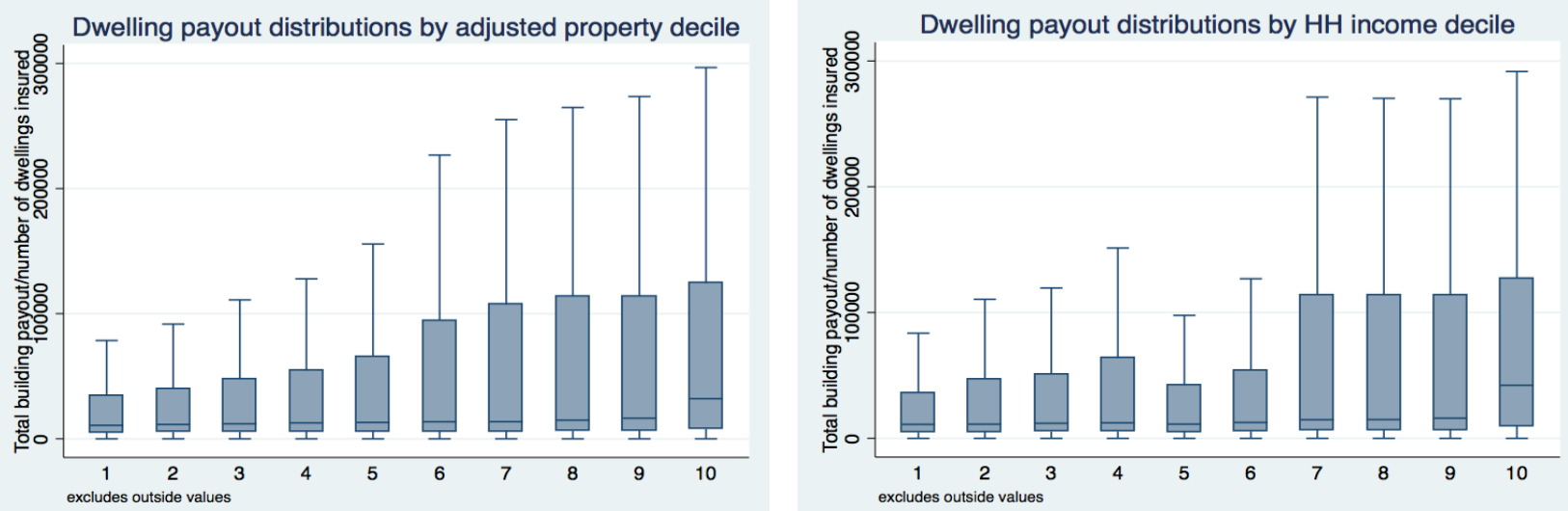

Figure 4: Distribution of Adjusted Building Payouts by Property Value and Income deciles - version 2 Standard Box and Whisker Plots - Canterbury dataset only, excludes zero value payouts. Distribution of payouts per property adjusted by number of dwellings insured by deciles of either dwelling adjusted modelled building value as at mid-2010, or meshblock level median household income as at 2006. 


\section{III - Details of Deciles used in figures:}

\begin{tabular}{|c|c|c|c|c|}
\hline & Mean & Sd & Min & $\operatorname{Max}$ \\
\hline 1 & $116,462.6$ & $31,019.67$ & $1,119.618$ & 155,316 \\
\hline 2 & $177,148.6$ & $11,479.42$ & 155,319 & $195,606.5$ \\
\hline 3 & $210,445.7$ & $8,154.632$ & 195,608 & 224,023 \\
\hline 4 & $237,217.5$ & $7,429.762$ & 224,026 & 249,910 \\
\hline 5 & $262,599.7$ & $7,411.955$ & 249,914 & 275,653 \\
\hline 6 & $289,586.8$ & $8,219.035$ & 275,658 & 304,188 \\
\hline 7 & $320,758.3$ & $9,916.973$ & 304,191 & 338,408 \\
\hline 8 & $359,794.6$ & $13,072.26$ & 338,411 & 384,055 \\
\hline 9 & 417,647 & $21,345.56$ & 384,062 & 458,800 \\
\hline 10 & 575,395 & $34,5308.5$ & 458,807 & $2.09 \mathrm{e}+07$ \\
\hline Total & $296,703.6$ & $166,466.6$ & $1,119.618$ & $2.09 \mathrm{e}+07$ \\
\hline
\end{tabular}

Table 6: Summary Statistics of Dwelling-Adjusted Property value, by decile.

This table shows the summary statistics of EQC supplied modelled property values as at mid-2010 in the Canterbury region, adjusted by the number of dwellings on the property.

\begin{tabular}{|c|c|c|c|c|}
\hline & Mean & Sd & Min & Max \\
\hline $\mathbf{1}$ & 26205.89 & 4240.017 & 5800 & 31700 \\
\hline $\mathbf{2}$ & 34095.26 & 1499.921 & 32500 & 36300 \\
\hline $\mathbf{3}$ & 39431.91 & 1777.227 & 36700 & 41700 \\
\hline $\mathbf{4}$ & 44285.97 & 1065.396 & 42500 & 45000 \\
\hline $\mathbf{5}$ & 48296.48 & 1554.835 & 45800 & 50800 \\
\hline $\mathbf{6}$ & 52388.76 & 933.4058 & 51100 & 54000 \\
\hline $\mathbf{7}$ & 57989.99 & 2080.846 & 55000 & 60000 \\
\hline $\mathbf{8}$ & 63702.22 & 1180.573 & 61400 & 65000 \\
\hline $\mathbf{9}$ & 72502.98 & 3546.156 & 66000 & 77500 \\
\hline $\mathbf{1 0}$ & 90038.24 & 7937.891 & 78600 & 100000 \\
\hline & 52058.53 & 18179.81 & & 5800 \\
\hline
\end{tabular}

Table 7: Summary Statistics of Meshblock Median Household Income as of 2006, by decile.

This table shows the summary statistics of Statistics New Zealand publicly available Census data on Median Household Income per meshblock in the Canterbury Region. 


\section{IV - Matching Process 41}

\section{The Matching Process - using the portfolioid and the geographic information}

In the EQC data, portfolioid consists of $0-\mathrm{N}$ claims and 1 property. In other words, there are zero, one or more claims associated with each portfolioid, and every property has a unique portfolioid.

The geographic information consists of lat-longs in the Property dataset, and meshblock polygons in the Meshblock Boundary files. These are geoprocessed to locate each property in it's (so far only 2016) meshblock.

\section{CLAIM DATASET}

\begin{tabular}{|l|l|}
\hline Unique identifier & claimid \\
\hline Foreign key & portfolioid \\
\hline
\end{tabular}

\section{PROPERTY DATASET}

\begin{tabular}{|l|l|}
\hline Identifiers: & $\begin{array}{l}\text { objectid } \\
\text { portfolioid }\end{array}$ \\
\hline $\begin{array}{l}\text { Variables for } \\
\text { matching: }\end{array}$ & $\begin{array}{l}\text { WQS84longitude } \\
\text { WQS84latitude }\end{array}$ \\
\hline $\begin{array}{l}\text { Geoprocessed } \\
\text { foreign key: }\end{array}$ & mb2016 \\
\hline
\end{tabular}

\section{MESHBLOCK BOUNDARY FILES}

\begin{tabular}{|l|l|}
\hline Unique identifier & mb2016 \\
\hline $\begin{array}{l}\text { Variables for } \\
\text { matching: }\end{array}$ & shape (GIS) \\
\hline
\end{tabular}

\section{Geoprocessing:}

1. Take objectid, WGS84lat \& WGS84long from property dataset (POINT)

2. Spatial-join to find shape from boundary files containing point (POLYGON)

3. Add meshblock number of polygon to point objectid as an additional variable/column 

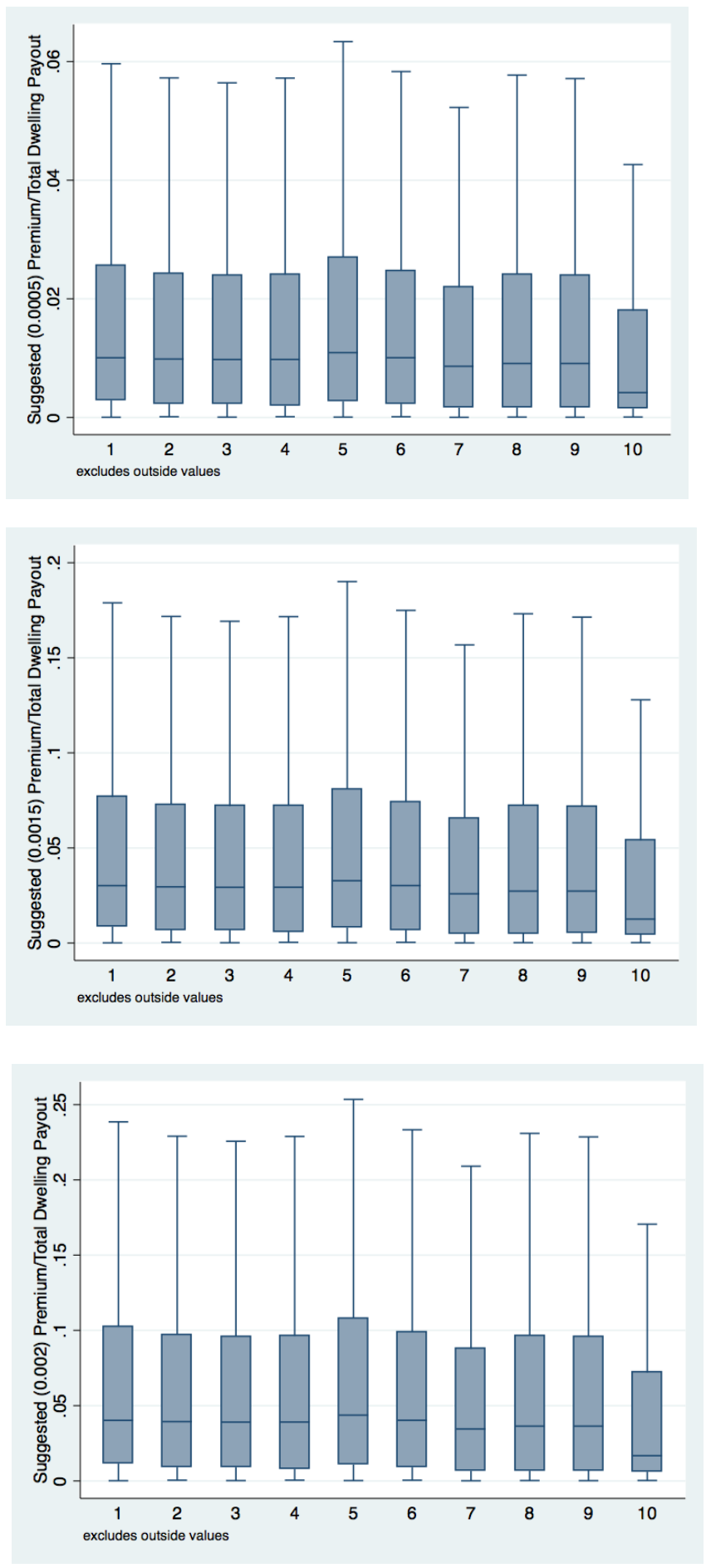

Figure 5: Premium to Payout Ratio for suggested premiums, by Median Household Income Decile This figure shows the distribution of Suggested Premium/Total Payout, where in panel 1 the suggested premium is calculated as 0.0005 times the dwelling-adjusted building value (pre quake), the second using 0.0015 and the third using 0.002. The Median Houehold Income values are at the meshblock level, and as at 2006. This figure also uses only the properties of building claimants from the Canterbury 2010-2011 earthquake series. Property and payout data supplied by EQC and confidential, income data collected by Statistics New Zealand in the 2006 Census. Dollars are NZ\$. 

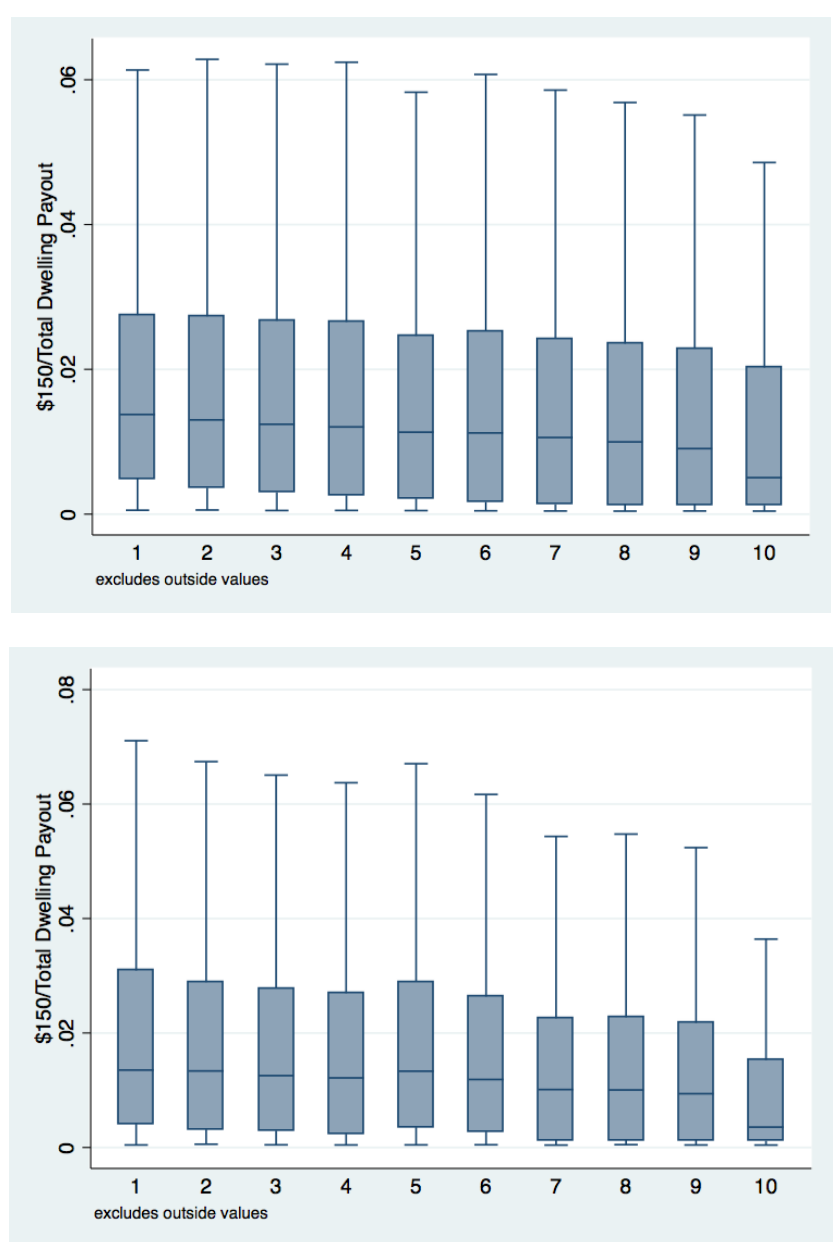

Figure 6: $\$ 150 /$ Total Building Payout by Building Value Decile then Median Household Income Decile

This figure shows the distribution of Suggested

Premium/Total Payout, where in panel 1 the suggested premium is calculated as 0.0005 times the dwelling-adjusted building value (pre quake), the second using 0.0015 and the third using 0.002. The building values are as at mid-2010. The Median Household Income values are at the meshblock level, and as at 2006. This figure also uses only the properties of building claimants from the Canterbury 2010-2011 earthquake series. Property and payout data supplied by EQC and confidential, in come data collected by Statistics New

Zealand in the 2006 Census. Dollars are NZ\$.Excludes outside values refers to the outliers of the box and whisker plots being omitted. 


\section{VII - EQC Supplied Data Documentation}

\section{Property data documentation}

\begin{tabular}{|l|l|}
\hline Description & Column Name \\
\hline PortfolioID - Property link to Claims & PortfolioID \\
\hline NZ region number (Quotable Value regions) & NZ Region Number \\
\hline Number of dwelling units & Number of Dwelling Units \\
\hline Modelled land value (\$) (for the 8m buffer EQC covers) & MLandValue_within8m \\
\hline Dwelling value (\$) (modelled) & MDwellingValue ${ }^{42}$ \\
\hline Appurtenant structures value (\$) (modelled) & MAppurtenantStructuresValue \\
\hline Domestic contents value (\$) (modelled) & MDomesticContentsValue \\
\hline NZ census Area Unit & NZ Census Area Unit \\
\hline Post code & Post Code \\
\hline WGS84 latitude (rounded to approximately 70m to protect privacy) & WGS84 Latitude \\
\hline WGS84 longitude (rounded to approximately 70m to protect privacy) & WGS84 Longitude \\
\hline
\end{tabular}

Properties that are in the portfolio may be mixed-use properties, but should always have at least some residential component.

Dollar amounts in the portfolio do not include GST.

\section{Claim data documentation}

\begin{tabular}{|c|c|}
\hline EQC Description (Own notes) & Column Name \\
\hline Internal claim identifier & ClaimID \\
\hline $\begin{array}{l}\text { EQC property identifier (not official). This is how we group } \\
\text { claims into properties for reporting purposes. EQCPropertyGroup } \\
\text { groups properties by EQC'S own property grouping algorithm, } \\
\text { attempting to group by address. }\end{array}$ & EqcPropertyGroup \\
\hline $\begin{array}{l}\text { Portfolio property identifier (foreign key to portfolio table). } \\
\text { PortfolioID groups properties in the same way that QV'S QPID does } \\
\text { - either by land parcel or dwelling. }\end{array}$ & PortfolioID \\
\hline Date of the event the claim is for & EventDate \\
\hline Date when the customer lodged the claim & ClaimOpenDate \\
\hline $\begin{array}{l}\text { Total estimated (if open) or actual (if closed - except EQR } \\
\text { payments*) cost to EQC for the building exposure }\end{array}$ & BuildingNetIncurred \\
\hline $\begin{array}{l}\text { Total estimated (if open) or actual (if closed) cost to EQC for the } \\
\text { contents exposure }\end{array}$ & ContentsNetIncurred \\
\hline Total cash paid to date for the building exposure & BuildingPaid \\
\hline Building exposure is closed/open/non-existent & BuildingClaimStatus \\
\hline $\begin{array}{l}\text { Date when the customer informed EQC that there was building } \\
\text { damage (usually when the overall claim was opened) }\end{array}$ & BuildingClaimOpenDate \\
\hline Date when the building portion of the claim was officially closed & BuildingClaimCloseDate \\
\hline Actual assessment estimated building repair cost & ActualAssessedBldgRepairCost \\
\hline $\begin{array}{l}\text { Total paid to date to EQR (for the Canterbury Home Repair } \\
\text { Programme) for repairs (may encompass multiple claims - see } \\
\text { below). Negative numbers are errors. }\end{array}$ & ManagedRepairPaid \\
\hline $\begin{array}{l}\text { Total amount paid to EQR for emergency works (included in } \\
\text { "ManagedRepairPaid") }\end{array}$ & EmergencyWorksPaid \\
\hline $\begin{array}{l}\text { Date Building repairs completed for the Canterbury Home } \\
\text { Repair Programme (may encompass repairs that cover multiple } \\
\text { claims - see below) }\end{array}$ & ManagedRepairCompletedDate \\
\hline $\begin{array}{l}\text { Apportioned estimated building repair cost attributed to this } \\
\text { claim }\end{array}$ & ApportionedBldgRepairCost \\
\hline
\end{tabular}

${ }^{42}$ Note the Modelled Dwelling values supplied were as-at-mid-2014. I requested and was given historical values of this variable, back to mid-2010. 


\begin{tabular}{|l|l|}
\hline Total cost to repair whole building used for apportionment & TotalApportionableBldgRepairCost \\
\hline Private building insurance company name & BuildingInsuranceCompany \\
\hline EQC insurance coverage verification status & BuildingEQCCoverageStatus \\
\hline Private building insurer policy status & BuildingInsurerPolicyStatus \\
\hline Building insurance coverage start date & BuildingCoverStartDate \\
\hline Building insurance policy type & BuildingPolicyType \\
\hline EQC building sum insured & EQCBuildingSumInsured \\
\hline Number of EQC-insured dwellings in this property for this claim & NumberofDwellingsInsured \\
\hline
\end{tabular}

All dollar amounts are in New Zealand dollars.

Net incurred and paid amounts include GST and are less deductible.

Assessment and apportioned amounts include GST, Preliminary and General (P\&G), and margin.

Sum insured includes GST.

Managed Repair Paid and Emergency Works Paid exclude GST. 


\section{References}

ABI (2011) Association of British Insurers responds to Government update on the future of flood insurance http://www.abi.org.uk/Media/ABI_Media_Statements/ABI_Media_Statements_2011. $\operatorname{aspx}$

Angrist, J. D., \& Pischke, J. S. (2008). Mostly harmless econometrics: An empiricist's companion. Princeton university press.

Ben-Shahar, O., \& Logue, K. D. (2015). Under the Weather: Government Insurance and the Regulation of Climate Risks. Coase-Sandor Working Paper Series in Law and Economics No. 714

Bento, A. M., Goulder, L. H., Jacobsen, M. R., \& Von Haefen, R. H. (2009). Distributional and efficiency impacts of increased US gasoline taxes. The American Economic Review, 99(3), 667-699.

Bin, O., Bishop, J. A., \& Kousky, C. (2012). Redistributional Effects of the National Flood Insurance Program. Public Finance Review, 40(3), 360-380.

Borren, P., \& Sutton, M. (1992). Are increases in cigarette taxation regressive? Health economics, 1(4), 245-253.

Cameron, A. C., \& Miller, D. L. (2015). A practitioner's guide to cluster-robust inference. Journal of Human Resources, 50(2), 317-372.

CCS (2008). Natural disaster insurance cover. A Diversity of Systems, Madrid: Consorcio de Compensacion de Seguros.

Davey, J. (2015). FloodRe: risk classification and 'Distortion of the Market.' In: Hjalmarsson, Johanna (eds.) Future Directions of Consumer Flood Insurance in the UK - Reflections upon the creation of FloodRe. University of Southampton, 26-33.

EQC (2011) Briefing to the Incoming Minister: December 2011, New Zealand Earthquake Commission

Evening Post (1941) War Damage, Evening Post, Volume CXXXII, Issue 149, 20 December 1941, Page 9 - Papers Past (National Library of New Zealand) website, https://paperspast.natlib.govt.nz/newspapers/evening-post/1941/12/20/9

Freeman, P. K., \& Scott, K. (2005). Comparative analysis of large scale catastrophe compensation schemes. Policy Issues in Insurance, 187-234.

Hjalmarrson et al (2015) Future directions of consumer flood insurance in the UK - reflections upon the creation of FloodRe.

Davis, L., \& Knittel, C. (2016). Are Fuel Economy Standards Regressive? (No. 22925). National Bureau of Economic Research.

Defra (2011b) Flooding and insurance: a roadmap to 2013 and beyond. Final Report of the Flood Insurance Working Groups. London: Defra 
Dlugolecki, A. (2009). Coping with climate change: risks and opportunities for insurers. Chartered Insurance Institute, London.

Henderson, A. (2010) 'Insurance - Disaster insurance', Te Ara - the Encyclopedia of New Zealand, http://www.TeAra.govt.nz/en/insurance/page-4

Howard, J. (2016). Socioeconomic Effects of the National Flood Insurance Program. Springer.

Hussain, A. (2008) Flood Insurance Blacklist Swells. The Sunday Times, News

Johnson, W. (2006). Are public subsidies to higher education regressive? Education, 1(3), 288315.

Joint Committee on Taxation (2015) Fairness and Tax Policy (JCX-48-15).

Kakwani, N. C. (1977). Measurement of tax progressivity: an international comparison. The Economic Journal, 87(345), 71-80.

Knight, F. H. (1921). Risk, uncertainty and profit. New York: Hart, Schaffner and Marx.

Kreimer, A., Arnold, M., \& Carlin, A. (2003). Building safer cities: the future of disaster risk. World Bank Publications.

Kunreuther, H. (2015). The role of insurance in reducing losses from extreme events: The need for public-private partnerships. Geneva Papers on Risk and Insurance: Issues and Practice, 40(4), 741-762.

Kunreuther, H., \& Pauly, M. (2009). Insuring Against Catastrophes. In: F. X. Diebold, N.J. Doherty and R.J. Herring (eds.). The Known, the Unknown and the Unknowable in Financial Risk Management. Princeton: Princeton University Press.

Lindley, S., O’Neill, J., Kandeh, J., Lawson, N., Christian, R., \& O’Neill, M. (2011). Climate change, justice and vulnerability. Joseph Rowntree Foundation, York.

Lyon, A. B., \& Schwab, R. M. (1991). Consumption taxes in a life-cycle framework: are sin taxes regressive? (No. 3932). National Bureau of Economic Research.

Marshall, D. (2017). The California Earthquake Authority. Discussion paper for Resources for the Future - Disaster Risk Financing.

McAneney, J., Crompton, R., McAneney, D., Musulin, R., Walker, G. \& Pielke Jr, R. (2013). Marketbased mechanisms for climate change adaptation: Assessing the potential for and limits to insurance and market based mechanisms for encouraging climate change adaptation, National Climate Change Adaptation Research Facility, Gold Coast

Medders, L. A., \& Nicholson, J. E. (2017). Florida's State Wind Pools. Discussion paper for Resources for the Future - Disaster Risk Financing.

Michel-Kerjan, E. O., \& Kousky, C. (2010). Come rain or shine: Evidence on flood insurance purchases in Florida. Journal of Risk and Insurance, 77(2), 369-397.

Monti, A. (2009). Climate Change and Weather-Related Disasters: What Role for Insurance, Reinsurance and Financial Sectors. Hastings West-Northwest. Journal of Environmental Law and Policy 15(1), 151-172. 
Musgrave, R. \& Thin, T. (1948). Income tax progression, 1929-48. Journal of Political Economy, 56(6), 498-514. Chicago.

Nelson, T., Simshauser, P., \& Nelson, J. (2012). Queensland solar feed-in tariffs and the meritorder effect: economic benefit, or regressive taxation and wealth transfers? Economic Analysis and Policy, 42(3), 277-301.

NZNSEE, (1993) Changes to disaster insurance in New Zealand, Bulletin NZ National Society for Earthquake Engineering, Vol.26, No.4, pp 437-444.

NZ Treasury (2015) New Zealand's Future Natural Disaster Insurance Scheme: Proposed changes to the Earthquake Commission Act 1993. Kaitohutohu Kaupapa Rawa- The New Zealand Treasury.

OECD (2016), Financial Management of Flood Risk, OECD Publishing, Paris. DOI: http://dx.doi.org/10.1787/9789264257689-en

OFM (2011) Memorandum to Cabinet: Increasing the Earthquake Commisson's Levy. Office of the Minister of Finance.

O'Neill, J., \& O'Neill, M. (2012). Social justice and the future of flood insurance. Joseph Rowntree Foundation.

Paudel, Y. (2012). A comparative study of public-private natural disaster insurance systems: lessons from current practices. Geneva Papers on Risk and Insurance: Issues and Practice, 37(2), 257-285.

Poterba, J. M. (1991a). Is the gasoline tax regressive? Tax policy and the economy, 5, 145-164.

Poterba, J. M. (1991b). Tax policy to combat global warming: on designing a carbon tax. In: Rudiger Dornbusch and James M. Poterba (eds.) Global Warming: Economic Policy Responses. Pp. 71-98. Cambridge, MA: MIT Press.

Slitor, R. E. (1948). The measurement of progressivity and built-in flexibility. The Quarterly Journal of Economics, 62(2), 309-313.

Surminski, S. (2014). The role of insurance in reducing direct risk: the case of flood insurance. International Review of Environmental and Resource Economics, 7(3-4), 241278.

Surminski S. (2017). Fit for purpose and fit for the future? An evaluation of the UK's new flood reinsurance pool. Resources for the Future Discussion Paper

Schwarze, R., Schwindt, M., Weck-Hannemann, H., Raschky, P., Zahn, F., \& Wagner, G. G. (2011). Natural hazard insurance in Europe: tailored responses to climate change are needed. Environmental Policy and Governance, 21(1), 14-30.

Thumim J., Fahmy, E. and White V. (2011) The distribution of UK household CO2 emissions: Interim report. York: Joseph Rowntree Foundation.

West, S. (2004). Distributional effects of alternative vehicle pollution control policies. Journal of Public Economics, 88(3), 735-757. 
Wier, M., Birr-Pedersen, K., Jacobsen, H. K., \& Klok, J. (2005). Are CO 2 taxes regressive? Evidence from the Danish experience. Ecological Economics, 52(2), 239-2 